\title{
1 Bimodal Distribution of Sulfuric Acid Aerosols in the Upper Haze of Venus
}

3 Peter Gao $^{1, *}$, Xi Zhang ${ }^{1,2}$, David Crisp ${ }^{3}$, Charles G. Bardeen ${ }^{4}$, and Yuk L. Yung ${ }^{1}$

4

$5{ }^{1}$ Division of Geological and Planetary Sciences, California Institute of Technology, Pasadena,

$6 \quad C A, U S A, 91125$

$7 \quad{ }^{2}$ Department of Planetary Sciences and Lunar and Planetary Laboratory, University of Arizona,

8 Tucson, AZ, USA, 85721

9 3et Propulsion Laboratory, California Institute of Technology, Pasadena, CA, USA, 91109

$10 \quad{ }^{4}$ National Center for Atmospheric Research, Boulder, CO, USA, 80307

11

12 *Corresponding author at: Division of Geological and Planetary Sciences, California Institute of

13 Technology, Pasadena, CA, USA, 91125

14 Email address: pgao@,caltech.edu

15 Phone number: 626-298-9098 


\section{Abstract}

17 Observations by the SPICAV/SOIR instruments aboard Venus Express have revealed that the upper haze (UH) of Venus, between 70 and $90 \mathrm{~km}$, is variable on the order of days and that it is populated by two particle modes. We use a one-dimensional microphysics and vertical transport model based on the Community Aerosol and Radiation Model for Atmospheres to evaluate whether interaction of upwelled cloud particles and sulfuric acid particles nucleated in situ on meteoric dust are able to generate the two observed modes, and whether their observed variability are due in part to the action of vertical transient winds at the cloud tops. Nucleation of photochemically produced sulfuric acid onto polysulfur condensation nuclei generates mode 1 cloud droplets, which then diffuse upwards into the UH. Droplets generated in the UH from nucleation of sulfuric acid onto meteoric dust coagulate with the upwelled cloud particles and therefore cannot reproduce the observed bimodal size distribution. By comparison, the mass transport enabled by transient winds at the cloud tops, possibly caused by sustained subsolar cloud top convection, are able to generate a bimodal size distribution in a time scale consistent with Venus Express observations. Below the altitude where the cloud particles are generated, sedimentation and vigorous convection causes the formation of large mode 2 and mode 3 particles in the middle and lower clouds. Evaporation of the particles below the clouds causes a local sulfuric acid vapor maximum that results in upwelling of sulfuric acid back into the clouds. In the case where the polysulfur condensation nuclei are small and their production rate is high, coagulation of small droplets onto larger droplets in the middle cloud may set up an oscillation in the size modes of the particles such that precipitation of sulfuric acid "rain" may be possible immediately below the clouds once every few Earth months. Reduction of the polysulfur condensation nuclei production rate destroys this oscillation and reduces the mode 1 particle abundance in the middle cloud by two orders of magnitude. However, it better reproduces the sulfur-to-sulfuric-acid mass ratio in the cloud and haze droplets as constrained by fits to UV reflectivity data. In general we find satisfactory agreement between our nominal and transient

42 wind results and observations from Pioneer Venus, Venus Express, and Magellan, though 43 improvements could be made by incorporating sulfur microphysics. 


\section{INTRODUCTION}

Sulfuric acid aerosols make up most of the global cloud deck and accompanying hazes

49 that shroud the surface of Venus (Esposito et al. 1983). As a result, the radiation environment and

50 energy budget at the surface and throughout the atmosphere is strongly affected by the vertical

51 extent, size distribution, and mean optical properties of these particles. These aerosols also serve

52 as a reservoir for sulfur and oxygen, and thus play a major part of the global sulfur oxidation

53 cycle (Mills et al. 2007). Furthermore, recent studies by Zhang et al. (2010; 2012a) have

54 hypothesized that the upper haze layer could provide the source of sulfur oxides above $90 \mathrm{~km}$.

55 Therefore, studying aerosols is a crucial step in understanding the climate and chemistry on

56 Venus.

57 Observations from the Pioneer Venus atmospheric probes (Knollenberg and Hunten

58 1980) helped constrain the number density and size distribution of the aerosols in the cloud deck,

59 and revealed the possibility of two size modes with mean radii $\sim 0.2 \mu \mathrm{m}$ (mode 1 ) and $\sim 1 \mu \mathrm{m}$

60 (mode 2), along with a third, controversial mode with radius $\sim 3.5 \mu \mathrm{m}$ whose existence has been

61 challenged (Toon et al. 1984). The clouds were also vertically resolved into three distinct

62 regions: the upper cloud, from 58 to $70 \mathrm{~km}$; the middle cloud, from 50 to $58 \mathrm{~km}$; and the lower

63 cloud, from 48 to $50 \mathrm{~km}$. Mode 1 particles have the largest number densities at all altitudes,

64 while modes 2 and 3 particles are relatively more abundant in the middle and lower clouds than

65 in the upper cloud (Knollenberg and Hunten 1980). Both entry probe (Knollenberg and Hunten

66 1980; Esposito et al. 1983) and remote sensing (Crisp et al. 1989; 1991; Carlson et al. 1993;

67 Grinspoon et al. 1993; Hueso et al. 2008) indicate that the middle and lower clouds are much

68 more variable than the upper cloud. This variability may be associated with strong convective

69 activity within the middle cloud, where downdrafts with amplitudes as large as $3 \mathrm{~m} \mathrm{~s}^{-1}$ and 
70 updrafts as large as $1 \mathrm{~m} \mathrm{~s}^{-1}$ were measured in situ by the VEGA Balloons (Ingersoll et al. 1987;

71 Crisp et al. 1990).

72 These observations of the Venus clouds have been interpreted using numerical models

73 that account for transport and/or aerosol microphysics. Toon et al. (1982) showed that sulfur

74 could be present in the upper cloud under low oxygen conditions in sufficient amounts to form

75 mode 1 particles, with mode 2 particles arising from the coagulation of these particles and

76 sulfuric acid droplets. However, they did not model any other interactions between sulfuric acid

77 and the sulfur particles beside coagulation. Krasnopolsky and Pollack (1994), meanwhile,

78 showed that the lower cloud is formed by upwelling and subsequent condensation of sulfuric

79 acid vapor due to the strong gradient in sulfuric acid mixing ratio below the clouds. James et al.

80 (1997) showed that this process is very sensitive to the local eddy diffusion coefficient, and

81 suggested that the variability of the lower and middle clouds was tied to the dynamical motions

82 of the atmosphere in this region. This conclusion was also reached by McGouldrick and Toon

83 (2007); they showed that organized downdrafts from convection and other dynamic processes

84 could produce holes in the clouds. Indeed, observations from Pioneer Venus indicated that this

85 region of the atmosphere has a lapse rate close to adiabatic, with parts of the middle cloud region

86 being superadiabatic (Seiff et al. 1980; Schubert et al. 1980). Imamura and Hashimoto (2001)

87 modeled the entire cloud deck, and reached many of the same conclusions as James et al. (1997)

88 and Krasnopolsky and Pollack (1994) regarding the lower and middle clouds, and Toon et al.

89 (1982) regarding the upper cloud. They also concluded that an upward wind may be necessary in

90 order to reproduce the observations.

91 The clouds lie below an upper haze (UH), which extends from 70 to $90 \mathrm{~km}$ (Mills et al.

92 2007). In Imamura and Hashimoto's model (2001), small cloud particles are lofted by upward 
93 winds out of the top of the model domain, which would place them in this UH. This

94 demonstrates that regional and/or global dynamical processes will lead to some mixing of the

95 haze with the clouds, resulting in variability of the particle populations in the UH, especially if

96 these processes vary with space and time. Though the variability of winds at the clouds-haze

97 boundary has never been measured directly, we do observe the particle population variability. For

98 instance, data from the Pioneer Venus Orbiter Cloud Photopolarimeter (OCPP) revealed

99 latitudinal variations of an order of magnitude in haze optical thickness from the polar region

100 (where it is more abundant) to the tropics, as well as temporal variations on the order of hundreds

101 of days (Kawabata et al. 1980). More recently, Wilquet et al. (2009, 2012) used Venus Express

102 SPICAV/SOIR solar occultation observations to show the existence of bimodality in the size

103 distribution of the UH, with a small mode of radius $0.1-0.3 \mu \mathrm{m}$, and a large mode of radius 0.4 -

$1041.0 \mu \mathrm{m}$. These modes are not to be confused with the aforementioned modes 1,2 , and 3 in the

105 cloud deck, even though they might be physically connected. Interestingly, the mean size of the

106 haze particles as reported by Kawabata et al. from OCPP measurements 30 years earlier $(0.23 \pm$

$1070.04 \mu \mathrm{m}$ ) lies well within the small mode size range. In addition, Wilquet et al. (2009) find that

108 the extinction of the haze was observed to vary by as much as an order of magnitude in a matter

109 of days. The degree of variability also changed, as observations a few months later (Wilquet et

110 al. 2012) showed variability in the magnitude of the haze extinction of only a factor of two. Time

111 variability of the haze was also observed in infrared images of the Venus southern hemisphere,

112 where the appearance of the haze changed dramatically across tens of degrees of latitude in the

113 span of a few days (Markiewicz et al. 2007). The three studies above also showed that the haze

114 optical depth can exceed unity, making it an active participant in the regulation of solar radiation

115 reaching lower altitudes, and its variability a property that requires better understanding. 
116 However, numerical models with adequate microphysics that include the UH are rare. Yamamoto

117 and Tanaka (1998) and Yamamoto and Takahashi (2006) included the UH in their simulations of

118 aerosol transport via global atmospheric dynamics and reproduced much of the observations

119 satisfactorily. However, the aerosol microphysics in both studies is inadequate due to the lack of 120 a detailed treatment of nucleation.

121 In this study, we investigate the formation and evolution of the $\mathrm{UH}$ and the cloud decks

122 by constructing a one-dimensional (1D) microphysical and vertical transport model that couples

123 the clouds to the haze with a more detailed treatment of the microphysics. We propose two

124 possible causes for the bimodal size distribution and time variability of the haze: (1) the two

125 modes are produced from two separate processes - one mode is derived from the in situ

126 nucleation of sulfuric acid onto meteoric dust, a possibility discussed by Turco et al. (1983) for

127 terrestrial atmospheres, and the other mode is made up of cloud particles that have been lofted

128 into the UH via winds and eddy diffusion, and (2) the two modes and the time variability are

129 entirely due to strong transient winds at the cloud tops lofting both mode 1 and mode 2 cloud

130 particles into the $\mathrm{UH}$.

131 We describe our basic model in section 2, with emphasis on the model attributes unique

132 to our investigation of aerosols in the Venus atmosphere. In section 3 we present our model

133 results, along with comparisons with data from Pioneer Venus and Venus Express. We also

134 discuss our results in the context of physical processes involved in our model. We summarize our 135 work and state our conclusions in section 4.

\section{2. MODEL}

138 We use version 3.0 of the Community Aerosol and Radiation Model for Atmospheres 
139 (CARMA) as our base microphysical and vertical transport code. The model is an upgrade from

140 the original CARMA (Turco et al. 1979, Toon et al. 1988) by Bardeen et al. (2008; 2011). We

141 describe our model setup and departures from the base model below, and we refer the reader to

142 Turco et al. (1979), Toon et al. (1988, 1989), and Jacobson et al. (1994) for detailed descriptions

143 of the basic microphysics and vertical transport and English et al. (2011) for the sulfate

144 microphysics in CARMA.

145 2.1. Model Setup

146 The microphysical and dynamical processes included in the model are the nucleation of

147 liquid sulfuric acid droplets on sulfur and meteoric dust condensation nuclei; the condensational

148 growth, evaporation, and coagulation of these particles; and their transport by sedimentation, 149 advection and diffusion.

150 Table 1 summarizes the simulation parameters. The model atmosphere extends from 40 to

$151100 \mathrm{~km}$, covering the altitudes of the cloud deck and UH. This vertical range is split into 300

152 levels of $200 \mathrm{~m}$ thickness each in our model. Our model time step is 10 seconds, and we found

153 that a total simulation time on the order of $2 \times 10^{8}$ seconds, or about 2000 Earth days, was

154 necessary for the model to reach steady state. This is similar to the characteristic vertical

155 diffusion time of the lower clouds as calculated from the eddy diffusion coefficient profile in

156 section 2.4 and far greater than that of the Venus mesosphere (i.e. the altitudes of the upper cloud 157 and upper haze) calculated by Imamura (1997).

158 In order to cover the size range from meteoric dust to large droplets and represent both

159 volatile and involatile particles, we use two groups of particle bins, each covering the radius

160 range from $1.3 \mathrm{~nm}$ to $\sim 30 \mu \mathrm{m}$. The lower radius limit corresponds to the size of meteoric dust as

161 described in Kalashnikova et al. (2000), while the upper radius limit mirrors the upper limit of 
162 Imamura and Hashimoto's model (2001). The inclusion of multiple bins for involatile particles

163 differs from the approach by Imamura and Hashimoto (2001), which only had the smallest

164 particle size bin allocated to involatile particles.

165 Figure 1 shows the temperature and pressure profiles used (Seiff et al. 1985), which were

166 fixed in the model. This is a simplification, as episodic increases in the temperatures of the Venus

167 upper mesosphere and lower thermosphere have been known to exist since they were first

168 observed by Clancy and Muhleman (1991). Such temperature increases have also been seen

169 more recently by the Venus Express SPICAV and SOIR instruments (Bertaux et al. 2007) and the

170 VeRa experiment (Tellmann et al. 2009). An increase in temperatures will suppress $\mathrm{H}_{2} \mathrm{SO}_{4}$

171 aerosol formation and enhance particle evaporation near the top of the domain studied here.

172 These temperature fluctuations will have little direct impact on the particle populations at lower

173 altitudes, but may indicate the presence of substantial changes in the dynamics of the

174 mesosphere, which could affect particle transport.

175 The production rates of sulfur and sulfuric acid depend on the chemical pathways that

176 lead to their production. Imamura and Hashimoto (2001) used

$$
3 \mathrm{SO}_{2}+2 \mathrm{H}_{2} \mathrm{O} \rightarrow \mathrm{S}+2 \mathrm{H}_{2} \mathrm{SO}_{4}
$$

178 (Yung and DeMore 1982; Krasnopolsky and Parshev 1983) as their primary reaction. However,

179 Yung and DeMore (1982) suggests that the main scheme for production of sulfuric acid is

180 actually

$$
\mathrm{SO}_{2}+\frac{1}{2} \mathrm{O}_{2}+\mathrm{H}_{2} \mathrm{O} \rightarrow \mathrm{H}_{2} \mathrm{SO}_{4}
$$

182 where the sulfur produced during the reaction is converted to $\mathrm{SO}$ via reaction with $\mathrm{O}_{2}$, though

183 their model still shows a net production of S. Furthermore, equation 1a is derived from Yung and 184 DeMore (1982)'s Model A, which is more appropriate for a Venus early in its evolution than the 
185 current Venus. Meanwhile, Krasnopolsky and Parshev (1983) note that the reaction that would

186 normally generate $\mathrm{S}, \mathrm{SO}+\mathrm{SO}$, could also go on to produce $\mathrm{S}_{2} \mathrm{O}$ instead. All of these

187 considerations suggest that the production rate of S is likely to be lower than half the production

188 rate of sulfuric acid, as suggested by equation 1a. On the other hand, Yung and DeMore (1982)

189 also showed that polysulfur can be produced and that sulfuric acid production (equation $1 \mathrm{~b}$ ) can

190 be suppressed via (SO) 2 dimer chemistry, while Toon et al. (1982) suggested that the primary

191 reaction can switch between equations $1 \mathrm{a}$ to $1 \mathrm{~b}$ depending on the local $\mathrm{O}_{2}$ content, which may be

192 variable. Therefore, it is uncertain what the sulfur production rate actually is. For simplicity, we

193 will use equation 1a as a basis for the production of sulfuric acid and sulfur, but we will also test

194 the effect of decreasing the sulfur production rate (section 3.3).

195 We begin each model run with no model-relevant species in the model box, e.g. no 196 sulfuric acid vapor or condensation nuclei of any kind. As each model run progresses, mass is 197 injected into the model atmosphere in the form of sulfuric acid vapor and involatile condensation 198 nuclei. The latter is split into two populations, one corresponding to photochemical products 199 (sulfur), and one corresponding to meteoric dust. Here, we assume a density of $1.9 \mathrm{~g} \mathrm{~cm}^{-3}$ for the 200 condensation nuclei, as an average between the density of sulfur $\left(1.8 \mathrm{~g} \mathrm{~cm}^{-3}\right.$, Imamura and 201 Hashimoto 2001) and meteoric dust (2.0 $\mathrm{g} \mathrm{cm}^{-3}$, Hunten et al. 1980). We use the same production 202 profiles of sulfuric acid vapor and photochemical condensation nuclei as Imamura and 203 Hashimoto (2001) for the production rates $\mathrm{P}_{\mathrm{H} 2 \mathrm{SO} 4}$ and $\mathrm{P}_{\mathrm{CN}}$, respectively:

$$
P_{C N}=\frac{1}{2} \Phi_{\mathrm{p}} \mathrm{g}(\mathrm{z})\left(\frac{\rho_{\mathrm{CN}}}{\mathrm{M}_{\mathrm{s}}} \frac{4}{3} \pi \mathrm{r}_{\mathrm{CN}}^{3}\right)^{-1} \mathrm{~cm}^{-3} \mathrm{~s}^{-1}
$$

206 where $\Phi_{p}$ is the column-integrated production rate of sulfuric acid vapor; the function $g(z)$ is a 207 Gaussian with a peak at $61 \mathrm{~km}$ altitude and full-width-half-max of $2 \mathrm{~km}$ such that 


$$
\int_{0}^{\infty} g(z) d z=1
$$

$\rho_{\mathrm{CN}}$ is the density of the condensation nuclei, $1.9 \mathrm{~g} \mathrm{~cm}^{-3} ; \mathrm{r}_{\mathrm{CN}}$ is the radius of the

210 condensation nuclei; and $\mathrm{M}_{\mathrm{s}}$ is the mass of a sulfur atom, $5.34 \times 10^{-23} \mathrm{~g}$. Our results showed that

211 agreement between model and data was best if $\Phi_{\mathrm{p}}$ was decreased from Imamura and

212 Hashimoto's (2001) nominal value of $10^{12} \mathrm{~cm}^{-2} \mathrm{~s}^{-1}$ to $6 \times 10^{11} \mathrm{~cm}^{-2} \mathrm{~s}^{-1}$, consistent with the

213 suppression of the sulfuric acid production rate discussed in Yung and DeMore (1982). Our

214 nominal production profiles are plotted in Figure 2.

215 The exact mechanics of how sulfuric acid nucleates onto condensation nuclei is not well

216 understood and this is made worse by the complexities of the chemistry in the Venus atmosphere.

217 As previously stated, we assume that the photochemical condensation nuclei are made of sulfur,

218 similar to the strategy of Imamura and Hashimoto (2001). However, this is a simplification, as

219 sulfur would likely exist in the form of polysulfur in the Venus clouds. Polysulfur would also

220 undergo the processes of nucleation, condensation, and evaporation similar to sulfuric acid

221 aerosols (Toon et al. 1982), with the only difference being that the polysulfur aerosols would

222 likely be solid at the temperatures of the upper cloud (Lyons 2008; Zhang et al. 2012a) and

223 therefore would not coagulate as efficiently as liquid aerosol droplets. Furthermore, as sulfuric

224 acid cannot actually wet sulfur (Young 1983), polysulfur cannot act as condensation nuclei in the

225 sense that they form cores that are completely encased within a layer of sulfuric acid. Instead, it

226 is more likely that sulfuric acid will only condense on a fraction of the total surface of a

227 polysulfur particle, and it is this small "drop" of condensed acid that then acts as the nucleation

228 site for more sulfuric acid. Thus, the actual particles would be made up of a polysulfur particle

229 stuck to the side of a droplet of sulfuric acid, with part of the polysulfur particle exposed to the

230 atmosphere. As Young (1983) elucidates, this has the effect of decreasing the efficiency of 
231 coagulation in the growth of these sulfuric acid aerosols, as now part of the surface is covered by

232 polysulfur and will not be able to participate in coagulation. In addition, as coagulation occurs,

233 more of the sulfuric acid particle's surface area will be covered by polysulfur (from particles it

234 coagulated with), further decreasing its coagulation rate. This has the effect of eventually

235 stopping coagulation altogether when the particle reaches a radius of $\sim 10 \mu \mathrm{m}$. While our model

236 does not distinguish whether the polysulfur "core" is within the sulfuric acid or attached to its

237 side, it does assume, for coagulation, that the entire surface is "available". We will discuss the

238 effect of this in section 3.1.

239 Further complicating the picture is the process opposite to the one we are modeling: the 240 nucleation of polysulfur onto sulfuric acid particles (Young 1983; Lyons 2008). Whether one

241 process dominates the other is determined by which particles homogeneously nucleates, i.e.

242 which one appears "first" to act as the condensation nuclei for the other. In this case, as the

243 saturation vapor pressure of most species of $S_{x}$ is an order of magnitude or more lower than that

244 of sulfuric acid in the cloud top region (Young 1983; Lyons 2008), we can safely assume that

245 polysulfur will homogeneously nucleate before sulfuric acid does so as to act as its condensation

246 nuclei and that we may ignore the opposite process. However, future studies should take into

247 account the aerosol physics of the polysulfur nuclei to investigate its effects on the cloud 248 distribution.

249 In our model, nucleation of sulfuric acid vapor onto the polysulfur condensation nuclei

250 occurs when the ambient sulfuric acid vapor concentration reaches a critical supersaturation. This

251 is determined by the sulfuric acid weight percent of the liquid that would form upon

252 condensation (see section 2.2) and the curvature of the surface on which the vapor will condense.

253 That is, we assume that the accommodation coefficient is unity. The curvature effect is 
254 determined by the Kelvin equation (Seinfeld and Pandis 2006):

$$
\operatorname{Ln} \frac{p}{p_{o}}=\frac{2 \gamma M}{\rho r R T}
$$

256 For our case, $p_{0}$ is the saturation vapor pressure over a flat surface; $p$ is the saturation vapor 257 pressure over a surface with curvature $r ; \gamma, \mathrm{M}$, and $\rho$ are the surface tension, molar mass, and 258 density of sulfuric acid, respectively; $\mathrm{R}$ is the gas constant; and $\mathrm{T}$ is the temperature. For 259 reasonable values of these parameters corresponding to $\sim 61 \mathrm{~km}$ in the Venus atmosphere, where 260 we use the parameterization of Mills (1996) for the surface tension, we find that the actual 261 saturation vapor pressure over condensation nuclei becomes an order of magnitude greater than 262 the saturation vapor pressure over a flat surface when the radius of the particle is $\sim 2 \mathrm{~nm}$. 263 However, given equation 2a, it will take on the order of hours for the sulfuric acid to build to 264 such concentrations, during which time the polysulfur condensation nuclei will also be growing, 265 thus increasing its radius of curvature and decreasing the saturation vapor pressure over its 266 surface. Therefore, there may exist an equilibrium point where the sulfuric acid concentration is 267 just high enough to begin nucleation onto the growing polysulfur particles. The calculation of 268 this equilibrium point is beyond the scope of this work, however, as our knowledge of the 269 kinetics of sulfur reactions is poor and thus we have ignored all microphysics (nucleation, 270 condensation, coagulation) associated with the condensation nuclei. Therefore, we will make a 271 simplification and assign a radius of $\sim 10 \mathrm{~nm}$ to the polysulfur condensation nuclei that are 272 injected into the model. Toon et al. (1982) simulated the microphysics of sulfur particles, but did 273 not take into account the effects of background sulfuric acid vapor or nucleation of said vapor on 274 the sulfur particles. It would be ideal to combine these processes to create a more complete 275 picture of the Venus clouds and hazes.

276 We adopt similar lower boundary conditions as those of Imamura and Hashimoto (2001), 
277 where involatile (sulfur) particles of size $\sim 0.17 \mu \mathrm{m}$ (mode 1) are fixed to have a number density

278 of $40 \mathrm{~cm}^{-3}$ in accordance with LCPS data (Knollenberg and Hunten 1980). We set the mixing

279 ratio of $\mathrm{H}_{2} \mathrm{SO}_{4}$ to be $3 \mathrm{ppm}$ at the lower boundary, within the $0-4 \mathrm{ppm}$ estimates from analysis of

280 Magellan radio occultation observations by Kolodner and Steffes (1998). We adopt a zero flux

281 boundary condition for the top boundary, as we assume that no particles or $\mathrm{H}_{2} \mathrm{SO}_{4}$ vapor escape

282 the mesosphere above $100 \mathrm{~km}$.

283 2.2. Thermodynamics of $\mathrm{H}_{2} \mathrm{SO}_{4}$

284 Of particular importance in this model is the treatment of certain thermodynamic 285 properties of $\mathrm{H}_{2} \mathrm{SO}_{4}$, such as its saturation vapor pressure and surface tension. Both of these 286 quantities control whether a sulfuric acid droplet is growing by condensation or evaporating.

287 The saturation vapor pressure $\mathrm{p}_{\mathrm{H} 2 \mathrm{SO} 4}$, in units of atm, is calculated via the equation of 288 Ayers et al. (1980), modified by Kulmala and Laaksonen (1990):

$$
\ln p_{\mathrm{H}_{2} \mathrm{SO}_{4}}=\ln p_{\mathrm{H}_{2} S O_{4}}^{0}+10156\left[-\frac{1}{T}+\frac{1}{T_{0}}+\frac{0.38}{T_{C}-T_{0}}\left(1+\ln \frac{T_{0}}{T}-\frac{T_{0}}{T}\right)\right]-\frac{H}{R T}
$$

290 where $T$ is temperature, $R$ is the universal gas constant, $T_{o}=340 \mathrm{~K}$ is a reference temperature, $T_{c}$ $291=905 \mathrm{~K}$ is the critical temperature, $\mathrm{p}^{0}{ }_{\mathrm{H} 2 \mathrm{SO} 4}$ is a reference pressure given by:

$$
\ln p_{H_{2} S O_{4}}^{0}=-\frac{10156}{T_{0}}+16.259
$$

293 and $\mathrm{H}$ is the enthalpy associated with the mixing of water and sulfuric acid, given by the 294 parameterization of Giauque (1959):

$$
H=4.184 \times 10^{7}\left[23624.8-\frac{1.14208 \times 10^{8}}{4798.69+\left(W_{\left.\mathrm{H}_{2} \mathrm{SO}_{4}-105.315\right)^{2}}\right.}\right] \mathrm{erg} \mathrm{mol}^{-1}
$$

296 where $\mathrm{W}_{\mathrm{H} 2 \mathrm{SO} 4}$ is the weight percentage of $\mathrm{H}_{2} \mathrm{SO}_{4}$ in the aerosol droplet calculated from 297 Tabazadeh et al. (1997) as a parameterization to temperature and background water vapor 298 concentration. 
The surface tension is derived from data collected by Sabinina and Turpugow (1935)

300 parameterized linearly with respect to temperature by Mills (1996). The value of the surface

301 tension at $\sim 61 \mathrm{~km}$ is given in Table 1 .

302 2.3. Water Vapor Profile

303 The base CARMA model does not treat the exchange of water between the background

304 water vapor concentration and the water taken up in the sulfuric acid cloud particles as they

305 grow. Instead, the weight percentage of water and sulfuric acid is always such that there is

306 equilibrium between the particle and the background water vapor concentration. In other words,

307 the model assumes the equilibrium aerosol growth regime (Zhang et al. 2012b). However, this

308 may not necessary be true given the low water vapor concentration in the Venus atmosphere

309 (Ignatiev et al. 1997). Therefore, we will assume an equilibrium background water vapor profile

310 that is fixed in time. Figure 3 shows this profile. Above $60 \mathrm{~km}$, we assume a water vapor

311 concentration of $\sim 1 \mathrm{ppm}$ in accordance with observations by Bertaux et al. (2007). Below $60 \mathrm{~km}$,

312 we model our profile after Model A of Ignatiev et al. (1997) and data from Venera 11, 13, and 14

313 (also taken from Ignatiev et al. 1997). The profile is empirically determined using an arctangent

314 function to connect the region above $60 \mathrm{~km}$ to the region below, and a Gaussian function to take

315 into account the water vapor concentration maximum at $\sim 53 \mathrm{~km}$ in Model A of Ignatiev et al.

316 (1997). The formula for the water vapor concentration (partial pressure), $\mathrm{P}_{\mathrm{H} 2 \mathrm{O}}$, is then

$$
\mathrm{P}_{\mathrm{H} 2 \mathrm{O}}=6 \times \exp \left[-\left(\frac{z-53}{8}\right)^{2}\right]-14.5\left(\frac{2}{\pi}\right) \tan ^{-1}(0.5 z-32.5)+15.5 \text { ppm }
$$

318 where $\mathrm{z}$ is in kilometers.

\subsection{Eddy Diffusion}

320 The eddy diffusion coefficient profile is shown in Figure 4. The values between 40 and

$32170 \mathrm{~km}$ altitude are approximated from Imamura and Hashimoto (2001) by fitting a function 
322 consisting of the sum of an exponential and a Gaussian function. The large increase in eddy

323 diffusion coefficient at $\sim 53 \mathrm{~km}$ simulates the convective overturning present in the middle cloud

324 as inferred from Schubert et al. (1980) and measured in situ by the VEGA Balloons (Ingersoll et

325 al. 1987; Crisp et al. 1990). The eddy diffusion coefficient above $70 \mathrm{~km}$ is approximated as a

326 Gaussian from Fig. 11 of Krasnopolsky (1983), which itself is generated from continuity

327 arguments with respect to the aerosol distribution observed in this region at the time. The

328 empirical formula of the eddy diffusion coefficient, $\mathrm{K}_{\mathrm{zz}}$, as a function of altitude $\mathrm{z}$ in kilometers

329 above $40 \mathrm{~km}$ is then:

330

$$
\mathrm{K}_{\mathrm{zz}}=10^{\frac{4 \mathrm{z}-160}{38.55}}+2500000\left\{\exp \left[-\left(\frac{z-52.5}{1.201}\right)^{2}\right]+\exp \left[-\left(\frac{z-100}{12.01}\right)^{2}\right]\right\} \mathrm{cm}^{2} s^{-1}
$$

331 To implement eddy diffusion in CARMA 3.0, we adopt similar numerical methods used by the

332 model to implement Brownian diffusion, except we replace the density of the species by its

333 mixing ratio. The upward and downward velocities of eddy diffusion of species $j, v_{u}^{j}$ and $v_{d}^{j}$,

334 respectively, are then given by:

$$
\begin{aligned}
& v_{u}^{j}=\ln \left(\frac{f_{i}^{j}}{f_{i-1}^{j}}\right) \frac{K_{z z}}{d z} \frac{f_{i-1}^{j}}{f_{i}^{j}-f_{i-1}^{j}} \mathrm{~cm} \mathrm{~s} \mathrm{~s}^{-1} \\
& v_{d}^{j}=\ln \left(\frac{f_{i}^{j}}{f_{i-1}^{j}}\right) \frac{K_{z z}}{d z} \frac{f_{i}^{j}}{f_{i}^{j}-f_{i-1}^{j}} \mathrm{~cm} \mathrm{~s} \mathrm{~s}^{-1}
\end{aligned}
$$

337 where $\mathrm{dz}$ is the thickness of an atmospheric layer (200 $\mathrm{m}$ in our model) and $\mathrm{f}_{\mathrm{i}}^{\mathrm{j}}$ is the mixing ratio 338 of species $\mathrm{j}$ in the ith layer. We can see that equations $7 \mathrm{a}$ and $7 \mathrm{~b}$ are diffusion velocities by 339 considering the continuous limit, where $\operatorname{Ln}\left(\mathrm{f}_{\mathrm{i}} / \mathrm{f}_{\mathrm{i}-1}\right)=\operatorname{Ln}\left(\mathrm{f}_{\mathrm{i}}\right)-\operatorname{Ln}\left(\mathrm{f}_{\mathrm{i}-1}\right) \sim \mathrm{d} \operatorname{Lnf}=\mathrm{df} / \mathrm{f}$, and $\mathrm{f}_{\mathrm{i}}-\mathrm{f}_{\mathrm{i}-1}=$ $340 \mathrm{df}$; the two df's and f's then cancel, resulting in $\mathrm{K}_{\mathrm{zz}} / \mathrm{dz}$, which is an eddy diffusion velocity scale.

341 This velocity is modulated by the mixing ratio gradient in our discrete case (i.e. $\operatorname{Ln}\left(\mathrm{f}_{\mathrm{i}} / \mathrm{f}_{\mathrm{i}-1}\right)$ does 342 not cancel with $\left.\mathrm{f}_{\mathrm{i}}\left(\mathrm{f}_{\mathrm{i}}-\mathrm{f}_{\mathrm{i}-1}\right)\right)$ such that large gradients lead to large velocities. The natural $\log$ 343 prevents numerical instabilities in the event the denominator becomes too small. 
Turco et al. (1983) discussed the properties of meteoric dust in the Venus atmosphere and concluded that it is similar to meteoric dust in the atmosphere of Earth and could act as

347 condensation nuclei to water vapor, forming thin ice hazes. We propose that meteoric dust could 348 also serve as condensation nuclei to sulfuric acid vapor, as its saturation vapor pressure is 349 extremely low at the altitude of the UH, on the order of $10^{-19}$ mbars for pure sulfuric acid, and $35010^{-31}$ mbars for a water-sulfuric acid mixture with $75 \mathrm{wt} \%$ sulfuric acid (Kulmala and Laaksonen 351 1990) that is typical of the UH (Kawabata et al. 1980). Thus, any sulfuric acid vapor that is lofted 352 into the UH by diffusion or winds could potentially condense on the meteoric dust present in this 353 region.

354 The Kelvin effect may play a large role in limiting the efficiency of meteoric dust as 355 condensation nuclei due to their small size. However, if we use the appropriate values for 356 sulfuric acid in the UH and a typical condensation nuclei size of $1.3 \mathrm{~nm}$ (Kalashnikova et al. 357 2000), then equation 3 yields an approximate increase of 2.4 orders of magnitude in the 358 saturation vapor pressure. This gives a resulting saturation vapor pressure of $\sim 10^{-29}-10^{-28}$ 359 mbars, which is far less than recent upper limits on the abundance of $\mathrm{H}_{2} \mathrm{SO}_{4}$ in the UH, e.g. 3 $360 \mathrm{ppb}$, or about $3 \times 10^{-9} \mathrm{mbar}$ at $80 \mathrm{~km}$, from Sandor et al. (2012). Therefore, meteoric dust should 361 act as very efficient condensation nuclei as long as the actual $\mathrm{H}_{2} \mathrm{SO}_{4}$ mixing ratio is not 362 significantly lower than this upper limit, even if the Kelvin effect is considered.

363 Meteoric dust is treated in the same way in our model as the sulfur condensation nuclei.

364 However, it is clear that meteoric dust, which is typically made of silicates (Hunten et al. 1980), 365 may react differently to sulfuric acid than sulfur. For example, Saunders et al. (2012) showed that 366 silicates dissolve in sulfuric acid on a timescale of an Earth week at the temperatures of the cloud 
367 tops. However, once the sulfuric acid droplet becomes much larger than the nucleus it condensed 368 on, the dissolution of said nucleus should have very little effect on the rest of the particle.

369 The production profile of meteoric dust we use in our model is shown in Figure 5 as an 370 empirical approximation of the profile calculated by Kalashnikova et al. (2000). All meteoric 371 dust particles are assumed to have a radius of $1.3 \mathrm{~nm}$. We have shifted the profile maximum from $37287 \mathrm{~km}$ to $83 \mathrm{~km}$ in order to match the maximum in the small mode curve in Fig. 9 of Wilquet et 373 al. (2009). The parameterization of the profile is given by:

$$
P_{m d}= \begin{cases}5 \times 10^{-3} e^{-\left(\frac{z-83}{2.402}\right)^{2}} & z \leq 83 \\ 5 \times 10^{-3} e^{-\left(\frac{z-83}{8.407}\right)^{2}} & z \geq 83\end{cases}
$$

375 where $\mathrm{z}$ has units of kilometers and $\mathrm{P}_{\mathrm{md}}$ has units of $\mathrm{cm}^{-3} \mathrm{~s}^{-1}$. Though this profile was applied to

376 Earth only, we will assume that it is also applicable to Venus due to the two planets' similarities.

377 However, if atmospheric density is the determining factor of the altitude of peak meteoric dust 378 ablation (e.g. Gadsden 1968) then our profile may be too low in the atmosphere. This is due to 379 the fact that the altitude on Venus with the same atmospheric density as that of the peak ablation 380 altitude on Earth is actually $\sim 110 \mathrm{~km}$.

381 2.6. Winds

In addition to testing the effects of the nucleation of sulfuric acid droplets on meteoric 383 dust on the UH particle size distribution, we will also test the effects of transient gusts at the 384 cloud tops. These are a separate set of simulations from the nominal runs described in section 385 2.1, though they do use the results of the nominal runs as initial conditions. Figure 6 shows the wind profile we use to test the effects of transient upward winds on the number density and size

387 distribution of the cloud and haze aerosols. The wind beneath $70 \mathrm{~km}$ is a constant flux wind 388 similar to that of Imamura and Hashimoto (2001) but increased in strength by two orders of 
magnitude to simulate a gust as opposed to a branch of the global circulation:

$$
w=\frac{8.0 \times 10^{-3}}{\rho} \mathrm{cm} \mathrm{s}^{-1}
$$

391 where $\mathrm{w}$ is upward wind speed and $\rho$ is atmospheric density, both in cgs units. In order to adhere

392 to our top boundary condition and simulate turning over of the wind currents, we allow the 393 upward wind to fall off linearly above $70 \mathrm{~km}$ so that it vanishes at $75 \mathrm{~km}$. This is consistent with 394 the strong static stability above that altitude.

395 Recent Venus Express observations of the Venus southern polar vortex at the altitude of 396 the upper cloud $(63-69 \mathrm{~km})$ show divergent and convergent circulations that imply vertical 397 velocities of $\sim 0.2 \mathrm{~m} \mathrm{~s}^{-1}$ (Garate-Lopez et al. 2013), roughly consistent with the lower limits of 398 our upper cloud wind velocities, though most of the vertical motions were downward rather than 399 upward. In addition, convective cells at the cloud tops have been observed at and downwind of 400 the Venus subsolar point (Belton et al. 1976; Titov et al. 2012). These have been interpreted 401 using 2D convection simulations as the incursion of the convective region in the middle cloud 402 into the stably stratified upper cloud (Baker et al. 1998; 1999), though some recent observations 403 suggest that the convective layer is thin enough that it may only occupy the upper cloud itself

404 (Markiewicz et al. 2007). The results of Baker et al. (1998) suggest that gravity waves 405 originating from the enlarged convective region could produce vertical velocities of $1-2 \mathrm{~m} \mathrm{~s}^{-1}$ at 406 and above $60 \mathrm{~km}$, matching our wind velocities at those altitudes.

407 Nevertheless, there are clear differences between our vertical advection scheme and the 408 actual advection processes in the Venus clouds. For instance, a realistic treatment of the gust 409 "turning over" above $70 \mathrm{~km}$ requires horizontal transport, which is beyond the scope of this 410 study. Thus, for the purpose of this work we will only examine qualitatively the effects of such a 411 gust on the cloud profile, such as the formation of a detached haze due to upwelled cloud 
412 particles, its destruction due to sedimentation and diffusion, the time scales involved, and the

413 changes in particle size distributions. In order to better evaluate these effects, we will magnify

414 them by considering gusts that last for $5 \times 10^{4}$ seconds, or $\sim 14$ Earth hours. Gusts in the polar

415 vortex may last as long, though as Venus Express orbits Venus on the same time scale ( $\sim 1$ Earth

416 day), the actual duration is uncertain. Winds caused by subsolar point convection may also be

417 able to last 14 hours, as convective features were seen up to $50^{\circ}$ latitude away from the equator

418 (Titov et al. 2012). This should also apply to longitude, and a distance of $50^{\circ}$ longitude away

419 from the subsolar point can be covered by the $\sim 100 \mathrm{~m} \mathrm{~s}^{-1}$ planet-encircling zonal winds at the

420 cloud tops (Schubert et al. 1980) in about 14 hours. In other words, each parcel of air could have

42114 hours during which gusts arising from subsolar convection can disrupt the aerosol particle

422 distributions therein before the convective cells give way to stably stratified regions.

423 Nevertheless, not only is the wind unlikely to be constant given the turbulent nature of its origin,

424 but Wilquet et al. (2009) observed the haze at $\sim 70^{\circ} \mathrm{N}$, a full $20^{\circ}$ latitude away from the

425 convective region. In short, we are not looking for exact agreement between our particle number

426 density and size distributions and one that is retrieved from observations, but rather whether we

427 can qualitatively reproduce the chaotic behavior of the UH.

\section{3. RESULTS AND DISCUSSION}

430 Our steady state results do not show a stable equilibrium distribution, but rather a quasi-

431 periodically varying distribution. Thus, we will proceed to compare to observations our results

432 from a single time step near the end of our nominal model run that best match them (section 3.1),

433 and then describe the mechanisms that could allow for such dynamics to occur despite a constant

434 background atmospheric state (section 3.2). In section 3.3 we discuss the effect of decreasing the 
435 sulfur production rate, and in section 3.4 we will describe our transient wind results.

436 3.1 Nominal Results

437 Figure 7 shows the number density predictions from our model for particles with radii 438 greater than $\sim 0.1 \mu \mathrm{m}$, which we choose as the lower size boundary of mode $1 /$ small mode 439 particles (Wilquet et al. 2009). We see that it is largely consistent with LCPS cloud data 440 (Knollenberg and Hunten 1980), though the middle cloud is overestimated by a factor of 3 and 441 the lower cloud is underestimated by a factor of $<2$. These differences are well within the range

442 of variability seen at these levels by the Pioneer Venus entry probes (Esposito et al. 1983), or in 443 near infrared observations of the Venus night side (Crisp et al. 1990; Grinspoon et al. 1993). 444 Figure 8 shows the size distributions of the cloud and haze particles at various altitudes. It 445 reproduces both the high number density of mode 1 particles in the upper cloud and the distinct 446 multi-modal nature of the middle and lower clouds' particle size distributions as seen by Pioneer 447 Venus (Knollenberg and Hunten 1980), including mode 1 at $\sim 0.2 \mu \mathrm{m}$, mode 2 at $\sim 1.4 \mu \mathrm{m}$, and 448 mode 3 (near the cloud base) at $\sim 3.5 \mu \mathrm{m}$. Comparison of this size distribution with Pioneer Venus 449 observations at $54.2 \mathrm{~km}$ (Knollenberg and Hunten 1980) shows clear agreement between the 450 model mode radii and that of the data, though a discrepancy exists in the mode abundances 451 there is an order of magnitude less mode 3 particles and $\sim 3$ times more mode 2 particles in our 452 model than in the observations. These discrepancies could be caused by the lack of transient 453 gusts in the middle and lower clouds of our steady state model, which Imamura and Hashimoto 454 (2001) showed could be used to produce a multi-modal structure in their model. Physically, 455 vertical gusts such as those detected in the middle cloud by the VEGA Balloons (Crisp et al. 456 1990) would both aid in the growth of mode 2 particles into mode 3 particles by introducing 457 "fresh" sulfuric acid from below (updrafts) and in the depletion of the middle cloud by 
458 downwelling the cloud particles (downdrafts); the depletion of the middle cloud is also a natural 459 consequence of the growth of particles, as these larger particles would have a faster 460 sedimentation time. Therefore, a series of vertical updrafts and downdrafts could lead to fewer 461 mode 2 particles, more mode 3 particles, and fewer particles in the middle cloud, resulting in 462 better agreement with data.

463 We assume that mode 3 particles are just larger versions of mode 2 particles, i.e. they are 464 liquid sulfuric acid droplets with a solid polysulfur component, but this need not be the case. In 465 fact, Knollenberg and Hunten (1980) discussed the possibility that mode 3 is made up of solid, 466 crystalline particles. On the other hand, Toon et al. (1984) suggested that mode 3 is in fact a large 467 particle tail of mode 2; our results support this latter interpretation, as the mode 3 particle peak 468 blends into the mode 2 peak somewhere between 54 and $58 \mathrm{~km}$ (figure 8). In light of the results 469 of Young (1983), however, we must consider the effect of solid polysulfur "patches" on the 470 surface of our sulfuric acid particles, which may make them seem like solid, crystalline particles 471 if the polysulfur coverage is high enough. As previously stated, the effect of these patches is the 472 decrease in the efficiency of coagulation in the removal of smaller particles, creating a smaller 473 number of larger particles. This could explain our underestimation of the lower cloud particle 474 number density, though it would also further overestimate our middle cloud particle number 475 density. Thus, a combination of decreased coagulation efficiency in larger particles and the 476 addition of middle cloud vertical gusts may be necessary to improve our model's agreement with 477 the Pioneer Venus Sounder Probe observations.

478 In the UH, our model predicts a steady state size distribution that is roughly mono-modal, 479 with a small "bump" at radii $>1 \mu \mathrm{m}$ corresponding to upwelled mode 2 particles that is largely 480 insignificant compared to the rest of the distribution. The lack of distinct bimodality despite the 
481 two different sources of particles is likely due to the effects of coagulation. In Figure 9, we 482 follow the time evolution of the upper haze at an altitude of $84 \mathrm{~km}$ during the first $\sim 4$ months of 483 the model run, long before steady state is reached. The green "bar" at $0.01 \mu \mathrm{m}$ is caused by the 484 artificial injection of $10 \mathrm{~nm}$ photochemical condensation nuclei into the model domain and 485 should be ignored. Immediately after the start of the simulation, a haze population emerges with 486 particle radii $<10 \mathrm{~nm}$. Such small particles could have only resulted from the nucleation of 487 sulfuric acid onto meteoric dust and subsequent condensational growth. Cloud droplets reach 84 $488 \mathrm{~km}$ one week later due to upward diffusion, which is followed by the disappearance of the 489 original meteoric-dust-derived haze population about a month afterwards. This suggests a 490 coagulation timescale of about a month to decrease the original population by about 2-3 orders of 491 magnitude, if indeed coagulation is the cause of this result. We can test whether this is physically 492 viable using the simplified solution to the discrete coagulation equation $\mathrm{N}(\mathrm{t})$ :

$$
N(t)=\frac{N_{0}}{1+\left(t / \tau_{c}\right)}
$$

494 where

$$
\tau_{c}=\frac{2}{K N_{0}}
$$

496 is a coagulation timescale. Here, $\mathrm{N}_{0}$ is the original number density, and $\mathrm{K}$ is the coagulation

497 kernel. For simplicity we use the continuum regime kernel, as particle number density is small, 498 and assume that the particle radii $\mathrm{R}_{2} \gg \mathrm{R}_{1}$ :

$$
K \sim \frac{2 k T}{3 \mu} \frac{R_{2}}{R_{1}}
$$

500 (Seinfeld and Pandis 2006). For a Boltzmann's constant $\mathrm{k}=1.38 \times 10^{-16} \mathrm{erg} \mathrm{K}^{-1}$, temperature T $501160 \mathrm{~K}$, atmospheric viscosity $\mu \sim 8 \times 10^{-5} \mathrm{~g} \mathrm{~cm}^{-1} \mathrm{~s}^{-1}$ and particle radii $\mathrm{R}_{1}=1 \mathrm{~nm}$ and $\mathrm{R}_{2}=100$

$502 \mathrm{~nm}$, we get a coagulation time needed to reduce the number density by $\sim 2-3$ orders of magnitude 503 of a few months, similar to our model results. Therefore we can conclude that the UH is likely a 
504 combination of upwelled cloud particles and particles nucleated in situ on meteoric dust, but that

505 the latter population has "fused" with the former, resulting in a mono-modal size distribution in

506 steady state. Thus, two separate sources of particles - one upwelled from below, and one

507 nucleated in situ cannot explain the bimodality detected by Kawabata et al. (1980) and Wilquet et

508 al. (2009). However, our peak model cloud top haze particle radius, $\sim 0.3 \mu \mathrm{m}$ at $70 \mathrm{~km}$, is fairly

509 close to the average haze particle radius originally detected by Kawabata et al. (1980) $(0.23 \pm$

$5100.04 \mu \mathrm{m})$. Furthermore, our UH size distribution covers the size range of both the small and the

511 large mode detected by Wilquet et al. (2009). Therefore, we propose that our results represent

512 both modes, and that something else is responsible for the splitting of the particle population into

513 two distinct modes. Figure 7 shows a comparison between the model number density and the

514 sum of the number densities of the two modes detected by Wilquet et al. (2009). The agreement

515 between model and data is satisfactory up to $80 \mathrm{~km}$, above which the model underestimates the

516 number density by about half an order of magnitude.

517 Alternatively, the meteoric dust production profile could be at a much higher altitude (see

518 section 2.5) such that they are above the upwelled cloud particles; the sulfuric acid droplets that

519 nucleate onto these meteoric dust particles would then have time to grow before they sediment

520 into the altitudes dominated by cloud droplets, with which they will coagulate as before. In this

521 scenario, the small mode would consist of both the upwelled cloud particles and the sedimenting

522 particles that nucleated in situ onto meteoric dust, while the larger mode would be made up of

523 the products of small mode coagulation. However, the resulting smaller $\mathrm{R}_{2} / \mathrm{R}_{1}$ ratio (equation 11 )

524 would increase the coagulation time scale and decrease the amount of large mode particles that

525 can be produced. Ultimately, the particles that nucleate from meteoric dust may be

526 inconsequential due to the lower flux of meteoric dust as compared to the flux of sulfuric acid 
vapor and sulfur.

Figure 10 shows a comparison between the predicted mixing ratio of sulfuric acid vapor

529 and the observed mixing ratio from Magellan radio occultation data as analyzed by Kolodner and

530 Steffes (1998). Though the large dispersion in the data from 0-6 ppm allows for a wide variety of

531 results to "fit" it, the physically relevant results are likely those that exhibit a local sulfuric acid

532 maximum below the clouds, and which also fit the nonzero data points. Indeed, our model results

533 show a satisfactory fit to the data points. While the bottom boundary condition fixes the vapor

534 concentration to $3 \mathrm{ppm}$ at $40 \mathrm{~km}$, the vapor concentration peak of $\sim 4.5 \mathrm{ppm}$ at the cloud base is

535 entirely due to sedimenting particles evaporating and depositing their sulfuric acid vapor at that

536 altitude. The peak value reflects a balance between the rate of vapor deposition and the upward

537 and downward vapor diffusion, and also imposes a constraint on the altitude of the cloud base,

538 below which any sulfuric acid droplets will be evaporating. Our results show that the cloud base

539 is at $\sim 47 \mathrm{~km}$, consistent with the model results of Krasnopolsky and Pollack (1994). Above the

540 cloud base, the vapor profile largely follows the saturation vapor pressure curve except at (1) 61

$541 \mathrm{~km}$, where sulfuric acid vapor is photochemically produced, and (2) above $80 \mathrm{~km}$. This latter

542 deviation may be caused by numerical instabilities caused by the low saturation vapor pressure

$543\left(\sim 10^{-31}\right.$ mbars $)$ or the phase properties of sulfuric acid and water solutions in this region

544 (McGouldrick et al. 2011).

$545 \quad$ Figure 11 shows number density as a function of both altitude and particle radius, while

546 figure 12 shows the sulfuric acid and particle mass fluxes for the middle cloud (top) and the

547 other altitudes (bottom); together they give a summary of the processes occurring in the clouds

548 and UH of Venus. The production of involatile sulfur condensation nuclei causes the nucleation

549 and condensational growth of liquid sulfuric acid droplets at $61 \mathrm{~km}$, resulting in a high number 
550 density of mode 1 particles. These particles then diffuse upwards and sediment downwards. The 551 positive divergence in the particle flux (in units of mass equivalent to $10^{12}$ sulfuric acid 552 molecules per unit area per second, where each molecule has mass $\sim 1.6 \times 10^{-22} \mathrm{~g}$ ) in this region 553 is clearly shown by the positive slope at $\sim 61 \mathrm{~km}$ in the lower panel of Figure 12 - particles 554 higher up has a smaller downward flux (i.e. a less negative flux) than the particles lower down. 555 There is no corresponding slope in the vapor flux curve as all the vapor is condensing onto the 556 particles. In the $\mathrm{UH}$, the upward diffusion of particles appears to balance the sedimentation, 557 leading to a near zero particle flux; the sulfuric acid vapor flux is also very close to zero, but it is 558 likely due to the small amount of vapor at these altitudes.

559 Below $61 \mathrm{~km}$, the vigorous convection in the middle cloud drives the large upward flux 560 of sulfuric acid vapor (top panel of figure 12), resulting in enhanced production of mode 2 561 particles as well as a tail of even larger particles resulting from coagulation. These particles, like 562 the upper cloud particles, are transported downwards by sedimentation and upwards by diffusion. 563 The latter process leads to a small large particle bump in the UH. These particles evaporate upon 564 reaching the cloud base, leading to the regeneration of mode 1 particles and the deposition of 565 sulfuric acid vapor beneath the clouds. The regenerated mode 1 is larger than the mode 1 of the 566 upper cloud due to the coagulation of the droplets higher up in the clouds - the cores of these 567 droplets are in effect added together, leading to the generation of larger involatile particles as the 568 larger cores are exposed upon droplet evaporation. This may not be what actually happens if the 569 "cores" are instead patches of polysulfur decorating the outside of the sulfuric acid droplets, as 570 per the "gumdrop" model of Young (1983). In this case, the "cores" would not be added together 571 and would remain the same size as their upper cloud counterparts upon the evaporation of the 572 sulfuric acid. Meanwhile, the tail of large particles forms a distinct third mode upon evaporation 
573 due to its slower evaporation rate as compared to that of the smaller mode 2 particles, which is a 574 product of the Kelvin effect (equation 3).

575 Below the clouds, the sulfuric acid vapor exhibits a negative flux as discussed previously,

576 while the particle flux is similarly negative, as the particles are sedimenting out of the bottom of

577 the model domain. The absolute value of the sum of the two fluxes at the bottom of the model

578 domain is $\sim 9 \times 10^{11} \mathrm{~cm}^{-2} \mathrm{~s}^{-1}$, slightly higher than the sum of the input flux of meteoric dust $(\sim 5 \mathrm{x}$

$\left.57910^{5} \mathrm{~cm}^{-2} \mathrm{~s}^{-1}\right)$, photochemical condensation nuclei $\left(\sim 10^{11} \mathrm{~cm}^{-2} \mathrm{~s}^{-1}\right)$, and sulfuric acid vapor $(6 \mathrm{x}$

$\left.58010^{11} \mathrm{~cm}^{-2} \mathrm{~s}^{-1}\right)$. This is due to the quasi-periodically varying nature of our results, i.e. we have

581 examined our simulated Venus cloud-haze system at a time when the flux out of the lower model

582 boundary is higher than what it should be for a steady state $\left(\sim 6.835 \times 10^{11} \mathrm{~cm}^{-2} \mathrm{~s}^{-1}\right)$.

\section{3.2. Periodic Behavior and Precipitation on Venus}

Figure 13 shows the time evolution of the particle size distribution at various altitudes.

585 Above the clouds, the quasi-periodic variations are very small, with amplitudes of no more than

$58610 \%$. In the upper cloud, the variations are larger with small hints of quasi-periodicity in the

587 mode 2 particle abundances apparent, but the size distribution is dominated by mode 1 particles,

588 which are fairly stable. In contrast, the middle cloud shows variations in particle abundances of 589 several orders of magnitude. All three modes appear to grow in radii with time and are 590 subsequently replaced with smaller particles on a time scale of $\sim 6$ Earth months. In particular, 591 mode 1 slowly grows to larger radii via coagulation and condensation until reaching $\sim 0.25 \mu \mathrm{m}$, 592 where there is a rapid growth of particles to mode 2 . This actually occurs at several points during 593 the slow migration of mode 1 particles to larger radii, as the intense eddy diffusion at $54 \mathrm{~km}$ will 594 allow any particles large enough to overcome the Kelvin barrier to grow rapidly. The upward 595 diffusion of mode 1 particles from below then "resets" the mean mode 1 particle radius back to 
$\sim 0.2 \mu \mathrm{m}$. Mode 2 then also grow slowly with time before growing somewhat rapidly into mode 3

597 particles, which then proceed to sediment into lower altitudes. The increase in mode 2 particle

598 growth rate occurs at nearly the same time as the rapid growth of mode 1 particles into mode 2

599 particles, possibly due to the coagulation of the "new" mode 2 particles among themselves and

600 with the "old" mode 2 particles, leading to the creation of the larger mode 3 particles.

601 Figure 13 also shows that, in comparison with the nominal/best-fit results in section 3.1,

602 the "usual state" of the Venus clouds is actually not those observed by the LCPS - for the

603 majority of the time, mode 2 has a mean radius of $\sim 1.2 \mu \mathrm{m}$ instead of the observed $1.4 \mu \mathrm{m}$

604 (Knollenberg and Hunten 1980), and it only grows to such a size right before the emergence of a

605 "new" mode 2.

606 This oscillation is apparently perpetuated by the growth of mode 1 particles into sizes 607 capable of overcoming the Kelvin Barrier, as that leads to the perturbation of the established 608 mode 2 particles which in turn leads to their growth into mode 3 particles. The growth of mode 1 609 particles can occur via coagulation among themselves, though it is more likely that the majority 610 of coagulation events are with the large number of smaller particles we use in our model as 611 photochemical condensation nuclei and which grew from those nuclei but have not yet reached 612 the sizes of the mode 1 particles, as coagulation between particles of vastly difference sizes is 613 faster than coagulation between similarly sized particles (Seinfeld and Pandis 2006). As such, 614 since each coagulation event would only add a very small amount of mass to each mode 1 615 particle, the growth would be gradual but steady, matching what we see in our model results. It is 616 interesting to note that this does not happen when we use a larger particle as our photochemical 617 condensation nuclei (e.g. Imamura and Hashimoto (2001)), as coagulation would be much 618 slower and "random" in time. These variations also do not happen to such an extent in the UH, as 
619 both the coagulation kernel (equation 11) and condensational growth rate are much lower there.

620 The quasi-periodic variability of the middle cloud leads to a quasi-periodic sedimentation

621 flux for the largest particles, which leads to the larger-than-expected bottom boundary flux in

622 figure 11. Figure 14 shows the time evolution of the sulfuric acid vapor and particle flux out of

623 the bottom boundary of the model domain, expressed in the same units as figure 12 . The average

624 of these oscillations, $6.765 \times 10^{11} \mathrm{~cm}^{-2} \mathrm{~s}^{-1}$ matches the injection rate of mass into the model

625 domain, $6.835 \times 10^{11} \mathrm{~cm}^{-2} \mathrm{~s}^{-1}$ fairly well, indicating that we are indeed at an equilibrium state.

626 Finally, we note that the particle and vapor flux oscillations are in phase with each other, and that

627 the latter has greater amplitude than the former. This is explained by the evaporation of the

628 particles below the cloud deck at $\sim 47 \mathrm{~km}$, such that the sulfuric acid variations from the middle

629 cloud are mostly expressed in the resulting vapor.

630 The possibility of such long term, quasi-periodic particle size variations provide

631 tantalizing hints towards possible sulfuric acid "rain" below the cloud decks of Venus, though we

632 use the term loosely as the downward mass fluxes associated with the "rain" in our model results

633 are far smaller than that of typical rain events on Earth. Nonetheless, it would be interesting to

634 search for evidence of their existence in VIRTIS observations of the Venus night side, which are

635 sensitive to such variations in particle population.

\subsection{Variations in the Sulfur Production Rate}

637 As discussed in section 2.1, the production rate of sulfur in the Venus atmosphere may be 638 much lower than half the production rate of sulfuric acid as implied by equation 1a due to 639 reactions of $\mathrm{S}$ with $\mathrm{O}_{2}$ and the formation of $\mathrm{S}_{2} \mathrm{O}$ instead of $\mathrm{SO}_{2}$ and $\mathrm{S}$ from the reaction $\mathrm{SO}+\mathrm{SO}$.

640 To address the effect decreasing the sulfur production would have on our results we rerun our 641 model with both one order of magnitude less sulfur produced and two orders of magnitude less 
642 sulfur produced. Figure 15 shows our results in terms of the number density (top) and size

643 distribution at $54 \mathrm{~km}$ in the middle cloud (bottom). Decreasing the sulfur condensation nuclei

644 production rate decreases the number of cloud droplets produced at all altitudes, but also

645 increases the average size of the droplets, since there are fewer nuclei for the same amount of gas

646 to condense on. Mode 1 particle abundances also decrease significantly in the middle cloud when

647 sulfur production is reduced, as the relative fraction of mode 1 particles that grow to mode 2

648 particles is now much larger. The disagreement between the observed size distribution and the

649 results of the reduced sulfur cases suggest that either (1) the primary reaction in the production of

650 sulfur is indeed reaction 1 a (section 2.1), and that $\mathrm{O}_{2}$ is relatively scarce in the upper cloud, or

651 (2) Pioneer Venus took data during a period of time when $\mathrm{SO}_{2}$ abundance exceeded $\mathrm{O}_{2}$

652 abundance, perhaps due to an updraft (Toon et al. 1982), and that the "steady state" size

653 distribution in the middle cloud is more akin to the reduced sulfur cases, with a low mode 1

654 abundance, or (3) our model is missing several pieces of essential physics, such as the

655 microphysics of the sulfur particles, which would otherwise result in greater mode 1 abundance

656 even when sulfur production is reduced. Option (3) is unfortunate but likely, given recent

657 modeling results by Carlson (2010, revisions via personal communication, Sept $2^{\text {nd }} 2013$ ), which

658 showed that the ratio between total sulfur mass and total sulfuric acid mass in the cloud droplets

659 is on the order of $0.1-1 \%$. We can calculate the same ratio for our model by adding up the masses

660 of the bare condensation nuclei and the sulfur cores of the sulfuric acid droplets and dividing it

661 by the mass of the sulfuric acid in the droplets. Figure 16 shows this ratio for our three sulfur

662 production rate cases. The sulfur-to-sulfuric-acid mass ratio steadily decreases with altitude until

663 the middle cloud, where it quickly decreases due to the turbulence in the region causing

664 increased condensation of sulfuric acid onto the droplets; the ratio increases below the middle 
665 cloud as sulfuric acid begins evaporating from the droplets. The best fit case is evidently one

666 where the sulfur production rate is one order of magnitude less than that of our nominal case, but

667 this contradicts figure 15, where that case did not yield enough mode 1 particles in the middle 668 cloud to match the observations. This discrepancy may be avoided if sulfur microphysics were

669 included in the model, as the small sulfur particles could then grow to larger sizes via 670 condensation of sulfur vapor, perhaps to sizes comparable to that of mode 1 particles. In other

671 words, the mass would be concentrated in mode 1 particles rather than the "sea" of smaller

672 condensation nuclei, even for the cases with reduced sulfur production.

673 Finally, it should be noted that the periodic behavior of the nominal case disappears in the

674 reduced sulfur cases. This is consistent with our hypothesis that the oscillation is caused by slow

675 growth of mode 1 particles due to coagulation with the background "sea" of much smaller 676 particles - if the "sea" is reduced, then coagulation may not be enough to allow mode 1 particles

677 to grow past the Kelvin barrier. This further suggests that the reduced sulfur cases match the true

678 state of the Venus clouds more closely than the nominal case, as no periodic behavior similar to

679 those in the nominal case has yet been observed.

$680 \quad 3.4$ Transient Wind Results

681 Figure 17 gives the number density results before (black), immediately after (blue), and 682 about an Earth week after a transient updraft event lasting $\sim 14$ Earth hours $\left(5 \times 10^{4} \mathrm{~s}\right)$ (red), 683 using the wind speed profile given in Figure 6. We see that a detached haze layer forms at $75 \mathrm{~km}$ 684 with a peak number density 2 orders of magnitude greater than the number density at that altitude 685 before the wind event. The altitude of the detached haze is likely artificial given our wind profile, 686 and the actual maximum detached haze number density is likely overestimated due to the lack of 687 horizontal diffusion aiding (the already present) vertical diffusion in smoothing out the number 
688 density profile. However, the occurrence of an increase in number density at the altitude of the 689 turn-over should be profile-independent. In the week that follows, the detached haze layer 690 diffuses away so that the peak number density is more than an order of magnitude lower than its 691 maximum immediately following the wind event. This shows that such a wind event produces 692 the right time scales for the observed haze variability from Wilquet et al. (2012), on the order of 693 days. Furthermore, the diffusion of the detached haze particles upwards results in an increase in 694 the number density of the UH such that there is now a much better agreement between the 695 Wilquet et al. (2009) UH number density observations and that of our model above $80 \mathrm{~km}$. It is 696 clear, however, that the agreement between data and model would be even better if the relaxed 697 distribution was shifted up by $10 \mathrm{~km}$. This suggests that the turnover was actually $10 \mathrm{~km}$ higher 698 in the actual observations, though it is unlikely that such large gusts existed at such high 699 altitudes.

Figure 18 shows the size distributions at altitudes close to the detached haze layer at the 701 same times as Figure 17. Multiple size modes form below the turnover of the wind immediately 702 following the wind event (blue). The small mode at $\sim 0.2 \mu \mathrm{m}$ is largely unchanged from the 703 equilibrium distribution for altitudes below the detached haze, but is much more abundant within 704 the detached haze itself at $75 \mathrm{~km}$; this is caused by the advection of these small particles up to 705 the altitude of the detached haze. The "bump" associated with the high altitude tail of the mode 2 706 cloud particles in the equilibrium distribution (black) becomes much more distinct due to upward 707 advection of more mode 2 particles; this feature is much more prominent below the detached 708 haze, which matches the observations of Wilquet et al. (2009) where the large UH particle mode 709 (mode 2 cloud particles) number density drops off with altitude much faster than the small UH 710 particle mode (mode 1 cloud particles). The small mode radii covers sizes $<0.6 \mu \mathrm{m}$, which is a 
711 larger range than the Wilquet et al. (2009) result of 0.1-0.3 $\mu \mathrm{m}$; the large mode radii covers the 712 sizes between 0.6 and $1 \mu \mathrm{m}$, similar to their results. Beyond $1 \mu \mathrm{m}$, the particle abundance drops 713 by over an order of magnitude, though a third mode does appear resulting from advected mode 3 714 cloud particles; however, it is insignificant compared to the small and large modes. Above the 715 turnover, the size distribution remains largely mono-modal.

716 Below the detached haze, the large mode becomes less distinct following the relaxation 717 period (red), though both modes increase in number density. This is due to the sedimentation of 718 large mode particles from the detached haze, as we see a large decrease in number density at the 719 altitude of the detached haze itself. There is also an increase in number density above the 720 turnover, as the detached haze particles diffuse upwards from the number density maximum. 721 Thus, if the bimodality observed by Wilquet et al. (2009) was caused by winds, then it was likely 722 transient in nature. This is supported by the order of magnitude variability between extinction 723 profiles of the UH taken only days apart presented in Wilquet et al. (2012). It is unlikely that 724 condensational and coagulational growth play any important role here, as their timescales are far 725 greater than the observed variability timescale (James et al. 1997; Seinfeld and Pandis 2006).

726 In section 2.6 we noted the unrealistic long gust duration we have used ( $\sim 14$ Earth hours).

727 However, we see that the UH size distribution is still visibly disturbed almost a full Earth week 728 after the wind event in question. If we suppose that our wind event is caused by subsolar 729 convection near $50^{\circ} \mathrm{N}$ that lasted for a full 14 hours and that the wind was constantly upwards 730 with velocity $\sim 1 \mathrm{~m} \mathrm{~s}^{-1}$ at the cloud top, then given poleward meridional velocities of $\sim 5 \mathrm{~m} \mathrm{~s}^{-1}$ 731 (Rossow et al. 1990) (a high estimate), it would take $\sim 1$ Earth week for this parcel of air to reach $73270^{\circ} \mathrm{N}$, the latitude where the measurements of Wilquet et al. (2009) were taken. It may not be 733 surprising then that our "relaxed" UH number density profile matches the Wilquet et al. (2009) 
734 number density data so well. However, most of these assumptions are highly optimistic and it is

735 much more likely that our results show an exaggeration of what transient winds at the cloud tops

736 can really do to the steady state aerosol distribution.

\section{SUMMARY AND CONCLUSIONS}

In this study we simulated the clouds and upper haze of Venus using version 3.0 of the 740 microphysical and vertical transport model CARMA. We showed that appropriate choices of

741 initial, boundary, and model atmospheric conditions can not only satisfactorily reproduce the

742 number density and size distributions of the Venus clouds as seen in Pioneer Venus data

743 (Knollenberg and Hunten 1980), including the bimodal and possible trimodal particle size

744 spectrum and the three separate cloud layers, but also generate a quasi-periodically varying 745 system rather than a system with a stable equilibrium distribution. The disagreements between 746 our results and the observations - the overestimation of the particle number density and 747 abundance of mode 2 particles in the middle cloud and the underestimation of the lower cloud 748 and the abundance of mode 3 particles - are all within the range of variability seen in other

749 observations, though the addition of transient gusts in the middle cloud, which would both 750 deplete the middle cloud of particles and create a greater number of larger particles, may 751 improve our agreement with the Pioneer Venus Sounder Probe data.

752 We also simulated the upper haze as a mixture of droplets formed from in situ nucleation 753 of sulfuric acid vapor on meteoric dust and droplets upwelled from the cloud decks below. We

754 showed that the former population rapidly coagulates with the latter population, resulting in a 755 mono-modal size distribution. Meanwhile, for altitudes below $80 \mathrm{~km}$ there is good agreement 756 between our model particle number densities and the sum of the small mode (mode 1) and large 
757 mode (mode 2) number densities from Wilquet et al. (2009); above $80 \mathrm{~km}$, we underestimate the

758 number density by about half an order of magnitude. These particles are likely those originally

759 observed by the Pioneer Venus OCPP (Kawabata et al. 1980), and could represent the haze under

760 stable atmospheric conditions. These discrepancies were reduced upon the application of a

761 transient updraft, which created a detached haze layer at the altitude of turnover. The diffusion of

762 the detached haze upwards increased the particle number density of the UH such that the results

763 agreed with the UH number densities derived by Wilquet et al. (2009) above $80 \mathrm{~km}$. The

764 resulting size distribution showed a clear bimodal structure below the detached haze immediately

765 after the wind event, with the small mode (mode 1) particles having radii $<0.6 \mu \mathrm{m}$, and the large

766 mode having radii between 0.6 and $1 \mu \mathrm{m}$, similar to the results of Wilquet et al. (2009). The

767 relaxation of the multi-modal structures in the size distribution back to a mono-modal

768 distribution had a timescale of roughly an Earth week, similar to the time scales of haze

769 variability observed by Venus Express (Luz et al. 2011, Markiewicz et al. 2007). The duration

770 and strength of the updraft were likely exaggerations of what actually takes place in the Venus

771 atmosphere, though subsolar convection could be a viable candidate for the generation of these

772 events under optimistic assumptions.

773 We noted a quasi-periodic variability in our results with a rough period of $\sim 6$ Earth

774 months despite a stable background atmospheric state and constant input of sulfuric acid vapor

775 and condensation nuclei. This variability is most apparent in the middle cloud, where steady

776 coagulation of small particles $(\sim 10 \mathrm{~nm})$ with mode 1 particles lead to a slow increase in the mean

777 mode 1 particle radii. Upon reaching the Kelvin barrier, the mode 1 particles rapidly grow to

778 mode 2 particles via condensational growth, while upward diffusion of mode 1 particles from

779 below replenish the mode 1 population. The cycle then repeats and a new wave of mode 2 
780 particles appear; these new mode 2 particles coagulate with the old mode 2 particles, resulting in 781 mode 3 particles that then sediment out of the model domain. This process does not occur if the 782 sulfur condensation nuclei production rate is decreased by an order of magnitude or more, nor 783 does it occur if the condensation nuclei are larger. Comparison between model results and 784 Pioneer Venus observations (Knollenberg and Hunten 1980) suggests that the LCPS data may 785 have been taken during one of the unstable "growth phases" rather than the much more long786 lived stable phases. These episodic variations also leads to periodicity in the magnitude of the 787 sulfuric acid flux out of the bottom boundary of the model domain and suggests possible sulfuric 788 acid "rain events" that could occur immediately below the cloud deck. Such long term variability 789 in particle population should be detectable by VIRTIS observations of the Venus night side.

790 The sulfur production rate in the upper cloud is uncertain and could be much lower than 791 half of the sulfuric acid production rate as assumed in Imamura and Hashimoto (2001) and in our 792 nominal model. Comparisons with sulfur-to-sulfuric-acid mass ratios of the cloud droplets 793 derived from UV data (Carlson 2010, revisions via personal communications, Sept $2^{\text {nd }} 2013$ ) 794 shows that the best fit case is one where the sulfur production rate is reduced by an order of 795 magnitude from that of the nominal case. However, comparison of this case with LCPS particle 796 size distributions shows that the model predicts mode 1 particle abundances in the middle cloud 797 two orders of magnitude less what is observed. This discrepancy could be caused by the lack of 798 sulfur microphysics in our model, which could allow the sulfur condensation nuclei to grow to 799 mode 1 particles $(\sim 0.2 \mu \mathrm{m})$ instead of being fixed at a size of $\sim 10 \mathrm{~nm}$.

800 It is necessary for future models to include both sulfur and sulfuric acid microphysics in 801 order to provide a more complete picture of the processes occurring within the Venus clouds and 802 hazes. Interactions between aerosols formed from these species and their gas phases are diverse 
803 and only a subset has been tested. Furthermore, the production rates of these two species,

804 particularly sulfur and its allotropes, require better constraints from both chemical models that

805 take into account sinks due to aerosol formation and observations that are able to probe down to

806 the altitudes where photochemistry dominates. Finally, continuous observation of the Venus

807 hazes and clouds is essential in constraining their time evolution, especially after transient

808 events.

809

\section{Acknowledgements}

811 We thank S. Garimella and R. L. Shia for assistance with the setting up and running of the 812 CARMA code. We thank R. W. Carlson and C. Parkinson for their valuable inputs. We thank C.

813 Li for his help in speeding up our model runs by more than a factor of 10 . This research was 814 supported in part by the Venus Express program via NASA NNX10AP80G grant to the 815 California Institute of Technology, and in part by an NAI Virtual Planetary Laboratory grant 816 from the University of Washington to the Jet Propulsion Laboratory and California Institute of

817 Technology. Part of the research described here was carried out at the Jet Propulsion Laboratory,

818 California Institute of Technology, under a contract with the National Aeronautics and Space 819 Administration. 

Ayers G. P., Gillett R. W., and Gras J. L. (1980) On the vapor pressure of sulfuric acid. Geophys. Res. Lett., 7, pp. 433-436.

Baker R. D., Schubert G., and Jones P. W. (1998) Cloud-level penetrative compressible convection in the Venus atmosphere. J. Atmos. Sci., 55, pp. 3-18.

Baker R. D., Schubert G., and Jones P. W. (1999) High Rayleigh number compression convection in Venus' atmosphere: Penetration, entrainment, and turbulence. J. Geophys. Res., 104, pp. 3815-3832.

Bardeen C. G., Toon O. B., Jensen E. J., Marsh D. R., and Harvey V. L. (2008) Numerical simulations of the three dimensional distribution of meteoric dust in the mesosphere and upper stratosphere. J. Geophys. Res., 113, D17202, 15pp.

Bardeen C. G., Conley A., Jensen E., Colarco P., Toon O., Fan T., and Smith J. (2011) The CARMA 3.0 microphysics package in CESM. Whole Atmosphere Working Group Meeting.

Barker E. S., Woodman J. H., Perry M. A., Hapke B. A., and Nelson R. (1975) Relative spectrophotometry of Venus from 3067 to 5960 Å. J. Atmos. Sci., 32, pp. 1205-1211.

Belton M. J. S., Smith G. R., Schubert G., and Del Genio A. D. (1976) Cloud patterns, waves and convection in the Venus atmosphere. J. Atmos. Sci., 33, pp. 1394-1417.

Bertaux J-L., Vandaele A-C., Korablev O., Villard E., Fedorova A., Fussen D., Quemerais E., Belyaev D., Mahieux A., Montmessin F., Muller C., Neefs E., Nevejans D., Wilquet V., Dubois J. P., Hauchecorne A., Stepanov A., Vinogradov I., Rodin A., and the SPICAV/SOIR team. (2007) A warm layer in Venus' cryosphere and high-altitude measurements of $\mathrm{HF}, \mathrm{HCl}, \mathrm{H}_{2} \mathrm{O}$, and $\mathrm{HDO}$. Nature, 450, pp. 646-649.

Carlson R. W., Kamp L. W., Baines K. H., Pollack J. B., Grinspoon D. H., Encrenaz Th., Drossart P., and Taylor F. W. (1993) Variations in Venus cloud properties: A new view of Venus's cloud morphology as observed by the Galileo Near-Infrared Mapping Spectrometer. Planet. Space Sci., 41, pp. 477-485.

Carlson R. W. (2010) Venus's ultraviolet absorber and sulfuric acid droplets. Paper presented at the International Venus Conference, Aussois, France, 20-26 June 2010.

Clancy R. T. and Muhleman D. O. (1991) Long-term (1979-1990) changes in the thermal, dynamical, and compositional structure of the Venus mesosphere as inferred from microwave spectral line observations of ${ }^{12} \mathrm{CO},{ }^{13} \mathrm{CO}$, and $\mathrm{C}^{18} \mathrm{O}$. Icarus, 89, pp. 129-146.

Crisp D., Sinton W. M., Hodapp K.-W., Ragent B., Gerbault, F., Goebel J. H., Probst R.G., Allen D. A., Pierce K., Stapelfeldt K. R. (1989) The nature of the near-infrared features on the Venus night side. Science, 246, pp. 506-509. 
Crisp D., Ingersoll A. P., Hildebrand C. E., and Preston R. A. (1990) VEGA Balloon meteorological measurements, Advanc. Space Res., 10, pp. 109-124.

Crisp D., McMuldroch S., Stephens S. K., Sinton W. M., Ragent B., Hodapp K.-W., Probst R. G., Doyle L. R., Allen D. A., and Elias J. (1991) Ground-based near-infrared imaging observations of Venus during the Galileo encounter. Science, 253, pp. 1538-1541.

English J. M., Toon O. B., Mills M. J., and Yu F. (2011) Microphysical simulations of new particle formation in the upper troposphere and lower stratosphere, Atmos. Chem. Phys., 11, pp. 9303-9322.

Esposito L. W., Knollenberg R. G., Marov M. Y., Toon O. B., and Turco R. P. (1983) In: The Press, Tucson, USA.

Gadsden M. (1968) Sodium in the upper atmosphere: Meteoric origin. J. Atmos. Terr. Phys., 30, pp. 151-161.

Garate-Lopez I., Hueso R., Sanchez-Lavega A., Peralta J., Piccioni G., and Drossart P. (2013) A chaotic long-lived vortex at the southern pole of Venus. Nat. Geosci., 6, pp. 254-257.

Giauque W. F., Hornung E. W., Kunzler J. E., and Rubin T. R. (1959) The thermodynamic properties of aqueous sulfuric acid solutions and hydrates from 15 to 300 K. J. Amer. Chem. Soc., 82, pp. 62-70.

Grinspoon D. H., Pollack J. B., Sitton B. R., Carlson R. W., Kamp L. W., Baines K. H., Encrenaz Th., and Taylor F. W. (1993) Probing Venus's cloud structure with Galileo NIMS. Planet. Space Sci., 41, pp. 515-542.

Hueso R., Sanchez-Lavega A., Piccioni G., Drossart P., Gerard J. C., Khatuntsev I., Zasova L., and Migliorini A. (2008) Morphology and dynamics of Venus oxygen airglow from Venus Express/Visible and Infrared Thermal Imaging Spectrometer observations. J. Geophys. Res., 113, E00B02, 7pp.

Hunten D. M., Turco R. P., and Toon O. B. (1980) Smoke and dust particles of meteoric origin in the mesosphere and stratosphere. J. Atmos. Sci., 37, pp. 1342-1357.

Ignatiev N. I., Moroz V. I., Moshkin B. E., Ekonomov V. I., Gnedykh A. V., Grigoriev A. V., and Khatuntsev I. V. (1997) Water vapour in the lower atmosphere of Venus: A new analysis of optical spectra measured by entry probes. Planet. Space Sci., 45, pp. 427-438.

Imamura T. (1997). Momentum balance of the Venusian midlatitude mesosphere. J. Geophys. Res., 102, pp. 6615-6620.

Imamura T. and Hashimoto G. L. (2001) Microphysics of Venusian clouds in rising tropical air. 
Ingersoll A. P., Crisp D., and the VEGA Balloon Science Team. (1987) Estimates of convective heat fluxes and gravity wave amplitudes in the Venus middle cloud layer from VEGA balloon measurements. Advanc. Space Res., 7, pp. 343-349.

Jacobson M. Z. and Turco R. P. (1994) Modeling coagulation among particles of different composition and size. Atmos. Environ., 28, pp. 1327-1338.

James E. P., Toon O. B., and Schubert G. (1997) A numerical microphysical model of the condensational Venus cloud. Icarus, 129, pp. 147-171.

Kalashnikova O., Horanyi M., Thomas G. E., and Toon O. B. (2000) Meteoric smoke production in the atmosphere. Geophys. Res. Lett., 27, pp. 3293-3296.

Kawabata K., Coffeen D. L., Hansen J. E., Lane W. A., Sato M., and Travis L. D. (1980) Cloud and haze properties from Pioneer Venus polarimetry. J. Geophys. Res., 85, pp. 8129-8140.

Knollenberg R. G. and Hunten D. M. (1980) The microphysics of the clouds of Venus: Results of the Pioneer Venus particle size spectrometer experiment. J. Geophys. Res., 85, pp. 8039-8058.

Kolodner M. A. and Steffes P. G. (1998) The microwave absorption and abundance of sulfuric acid vapor in the Venus atmosphere based on new laboratory measurements. Icarus, 132, pp. 151-169.

Krasnopolsky V. A. (1983) In: Venus spectroscopy in the 3000-8000 A region by Veneras 9 and 10, in Venus, edited by Hunten, D. M. et al., pp. 459-483. Univ. of Ariz. Press, Tucson, USA.

Krasnopolsky V. A. and Parshev V. A. (1983) In: Photochemistry of the Venus atmosphere, in Venus, edited by Hunten, D. M. et al., pp. 431-458. Univ. of Ariz. Press, Tucson, USA.

Krasnopolsky V. A. and Pollack J. B. (1994) $\mathrm{H}_{2} \mathrm{O}-\mathrm{H}_{2} \mathrm{SO}_{4}$ system in Venus' clouds and OCS, $\mathrm{CO}$, and $\mathrm{H}_{2} \mathrm{SO}_{4}$ profiles in Venus' troposphere. Icarus, 109, pp. 58-78.

Kulmala M. and Laaksonen A. (1990) Binary nucleation of water-sulfuric acid system: Comparison of classical theories with different $\mathrm{H}_{2} \mathrm{SO}_{4}$ saturation vapor pressures. J. Chem. Phys., 93, pp. 696-701.

Luz D., Berry D. L., Piccioni G., Drossart P., Politi R., Wilson C. F., Erard S., and Nuccilli F. (2011) Venus's southern polar vortex reveals precessing circulation. Science, 332, pp. 577-580.

Lyons J. R. (2008) An estimate of the equilibrium speciation of sulfur vapor over solid sulfur and implications for planetary atmospheres. J. Sulfur Chem., 29, pp. 269-279.

Markiewicz W. J., Titov D. V., Limaye S. S., Keller H. U., Ignatiev N., Jaumann R., Thomas N., Michalik H., Moissl R., and Russo P. (2007) Morphology and dynamics of the upper cloud layer 
of Venus. Nature, 450, pp. 633-636.

961

962

963

964

965

966

967

968

969

970

971

972

973

974

975

976

977

978

979

980

981

982

983

984

985

986

987

988

989

990

991

992

993

994

995

996

997

998

999

1000

1001

1002

1003

1004

1005

McGouldrick K. and Toon O. B. (2007) An investigation of possible causes of the holes in the condensational Venus cloud using a microphysical cloud model with a radiative-dynamical feedback. Icarus, 191, pp. 1-24.

McGouldrick K., Toon O. B., and Grinspoon D. H. (2011) Sulfuric acid aerosols in the atmosphere of the terrestrial planets. Planet. Space Sci., 59, pp. 934-941.

Mills F. P., Esposito L. W., Yung Y. L. (2007) In: Atmospheric composition, chemistry, and clouds, in Exploring Venus as a Terrestrial Planet, edited by Esposito, L. W. et al., pp. 73-100. American Geophysical Union, Washington D.C., USA.

Mills M. J. (1996) Stratospheric sulfate aerosol: A microphysical model. PhD thesis at the University of Colorado, Department of Astrophysical, Planetary, and Atmospheric sciences.

Rossow W. B., Del Benio A. D., and Eichler T. (1990) Cloud-tracked winds from Pioneer Venus OCPP images. J. Atmos. Sci., 47, pp. 2053-2084.

Sabinina L. and Turpugow L. (1935) The surface tension of the system sulfuric acid-water. $Z$. Phys. Chem., A173, pp. 237-241.

Sandor B. J., Clancy R. Todd, and Moriarty-Schieven G. (2012) Upper limits for $\mathrm{H}_{2} \mathrm{SO}_{4}$ in the mesosphere of Venus. Icarus, 217, pp. 839-844.

Saunders R. W., Dhomse S., Tian W. S., Chipperfield M. P., and Plane J. M. C. (2012) Interactions of meteoric smoke particles with sulphuric acid in the Earth's stratosphere. Atmos. Chem. Phys., 12, pp. 4387-4398.

Schubert G., Covey C., Del Genio A., Elson L. S., Keating G., Seiff A., Young R. E., Apt J., Counselman III, C., Kliore A. J., Limaye S. S., Revercomb H. E., Sromovsky L. A., Suomi V. E., Taylor F., Woo R., and von Zahn U. (1980) Structure and circulation of the Venus atmosphere. $J$. Geophys. Res., 85, pp. 8007-8025.

Seiff A., Kirk D. B., Young R. E., Blanchard R. C., Findlay J. T., Kelly G. M., and Sommer S. C. (1980) Measurements of thermal structure and thermal contrasts in the atmosphere of Venus and related dynamical observations: Results from the four Pioneer Venus probes. J. Geophys. Res., 85, pp. 7903-7933.

Seiff A., Schofield J. T., Kliore A. J., Taylor F. W., Limaye S. S., Revercomb H. E., Sromovsky L. A., Kerzhanovich V. V., Moroz V. I., and Marov M. Ya. (1985) Models of the structure of the atmosphere of Venus from the surface to 100 kilometers altitude. Adv. Space Res., 5, pp. 3-58.

Seinfeld J. H. and Pandis S. N. (2006) In: Atmospheric chemistry and physics: From air pollution to climate change, $2^{\text {nd }}$ edition. John Wiley \& Sons, Inc. Hoboken, New Jersey, USA. 
1006

1007

1008

1009

1010

1011

1012

1013

1014

1015

1016

1017

1018

1019

1020

1021

1022

1023

1024

1025

1026

1027

1028

1029

1030

1031

1032

1033

1034

1035

1036

1037

1038

1039

1040

1041

1042

1043

1044

1045

1046

1047

1048

1049

1050

1051
Tabazadeh A., Toon O. B., Clegg S. L., and Hamill P. (1997) A new parameterization of $\mathrm{H}_{2} \mathrm{SO}_{4} /$ $\mathrm{H}_{2} \mathrm{O}$ aerosol composition: Atmospheric implications. Geophys. Res. Lett., 24, pp. 1931-1934.

Tellmann S., Patzold M., Hausler B., Bird M. K., and Tyler G. L. (2009) Structure of the Venus neutral atmosphere as observed by the Radio Science experiment VeRa on Venus Express. $J$. Geophys. Res. 114, E00B36, 19pp.

Titov D. V., Markiewicz W. J., Ignatiev N. I., Song L., Limaye S. S., Sanchez-Lavega A., Hesemann J., Almeida M., Roatsch T., Matz K-D., Scholten F., Crisp D., Esposito L. W., Hviid S. F., Jaumann R., Keller H. U., and Moissl R. (2012) Morphology of the cloud tops as observed by the Venus Express Monitoring Camera. Icarus, 217, pp. 682-701.

Toon O. B., Turco R. P., and Pollack J. B. (1982) The ultraviolet absorber on Venus: Amorphous sulfur. Icarus, 51, pp. 358-373.

Toon O. B., Ragent B., Colburn D., Blamont J., and Cot C. (1984) Large, solid particles in the clouds of Venus: Do they exist? Icarus, 57, pp. 143-160.

Toon O. B., Turco R. P., Westphal D., Malone R., and Liu M. S. (1988) A multidimensional model for aerosols: Description of computational analogs. J. Atmos. Sci., 45, pp. 2123-2143.

Toon O. B., Turco R. P., Jordan J., Goodman J., and Ferry G. (1989) Physical processes in polar stratospheric ice clouds. J. Geophys. Res., 94, pp. 11359-11380.

Turco R. P., Hamill P., Toon O. B., Whitten R. C., and Kiang C. S. (1979) A one-dimensional model describing aerosol formation and evolution in the stratosphere: I. Physical processes and mathematical analogs. J. Atmos. Sci., 36, pp. 699-717.

Turco R. P., Toon O. B., Whitten R. C., and Keesee R. G. (1983) Venus: Mesospheric hazes of ice, dust, and acid aerosols. Icarus, 53, pp. 18-25.

White F. M. (1991) In: Viscous Fluid Flow. McGraw-Hill, New York, USA.

Wilquet V., Drummond R., Mahieux A., Robert S., Vandaele A. C., and Bertaux J.-L. (2012) Optical extinction due to aerosols in the upper haze of Venus: Four years of SOIR/VEX observations from 2006 to 2010. Icarus, 217, pp. 875-881.

Wilquet V., Fedorova A., Montmessin F., Drummond R., Mahieux A., Vandaele A. C., Villard E., Korablev O., and Bertaux J.-L. (2009) Preliminary characterization of the upper haze by SPICAV/SOIR solar occultation in UV to mid-IR onboard Venus Express. J. Geophys. Res., 114, E00B42, 13pp.

Yamamoto M. and Tanaka H. (1998) The Venusian Y-shaped cloud pattern based on an aerosoltransport model. J. Atmos. Sci., 55, pp. 1400-1426.

Yamamoto M. and Takahashi M. (2006) An aerosol transport model based on a two-moment 
1052 microphysical parametrization in the Venus middle atmosphere: Model description and 1053 preliminary experiments. J. Geophys. Res., 111, E08002, 12pp.

1054

1055

1056

1057

1058

1059

1060 Zhang X., Liang M. C., Montmessin F., Bertaux J. L., Parkinson C., and Yung Y. L. (2010)

1061 Photolysis of sulphuric acid as the source of sulphur oxides in the mesosphere of Venus. Nat.

1062 Geosci., 3, pp. 834-837.

1063

1064 Zhang X., Liang M. C., Mills F. P., Belyaev D., and Yung Y. L. (2012a) Sulfur chemistry in the

1065

1066

1067 middle atmosphere of Venus. Icarus, 217, pp. 714-739.

1068

Zhang X., Pandis S. N., and Seinfeld J. H. (2012b) Diffusion-limited versus quasi-equilibrium 1069 


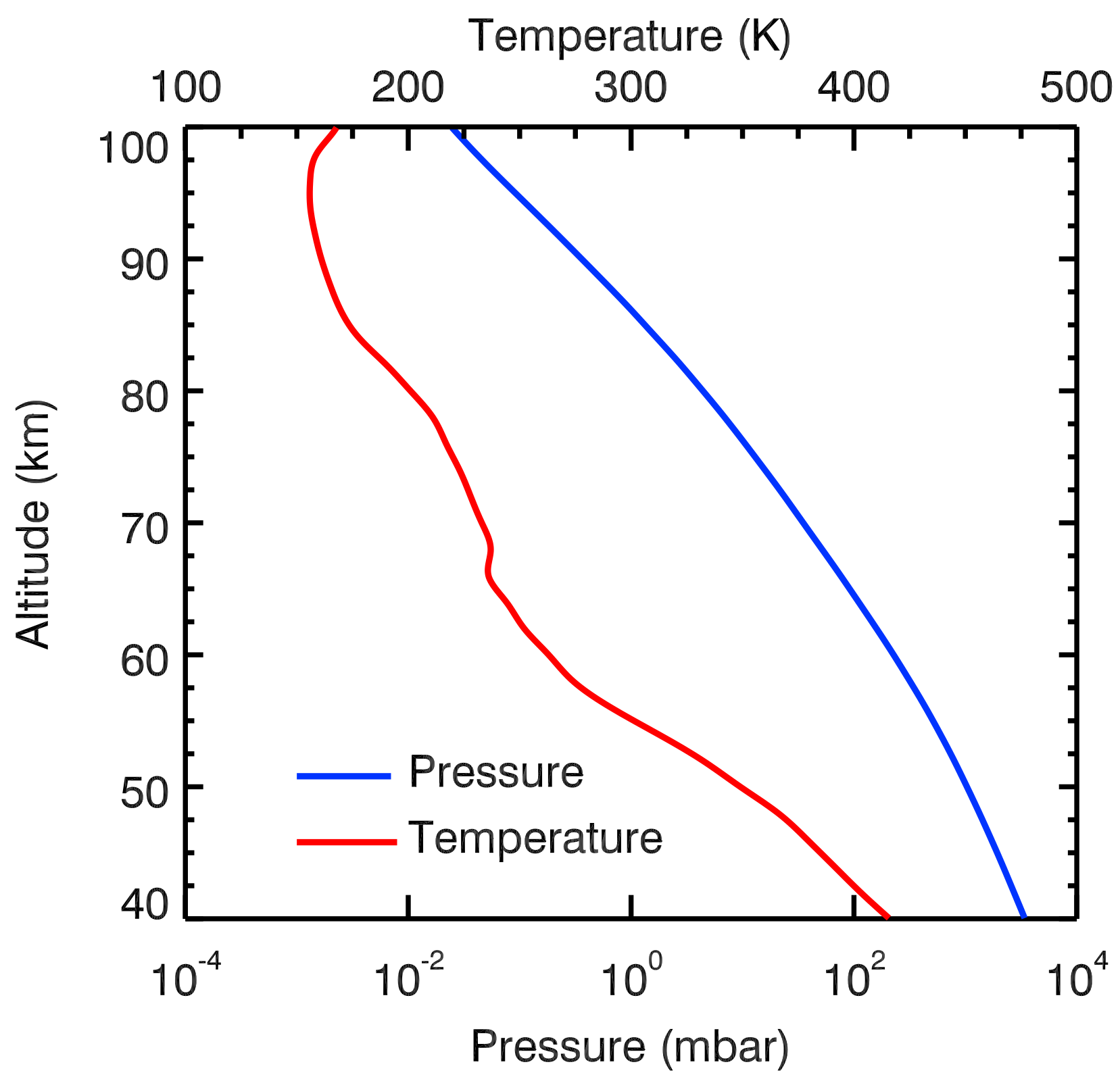

Figure 1. Model temperature (red) and pressure (blue) profiles taken from the Venus 1073 1074 


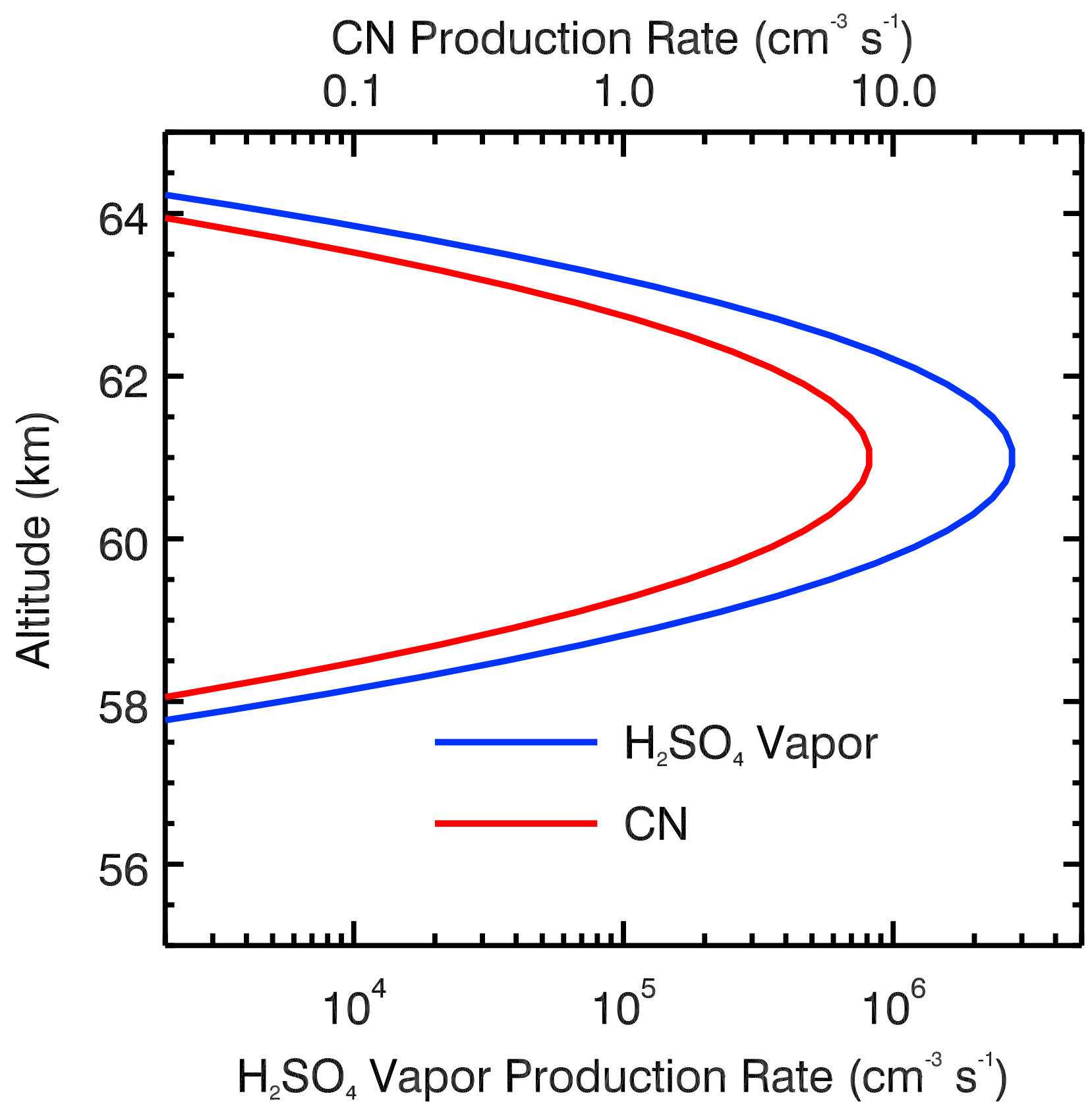

1076

1077

1078

1079

Figure 2. Model production rate profiles for sulfuric acid vapor (blue) and photochemical condensation nuclei (red), based on that of Imamura and Hashimoto (2001) with the peak rates adjusted to fit LCPS data. 


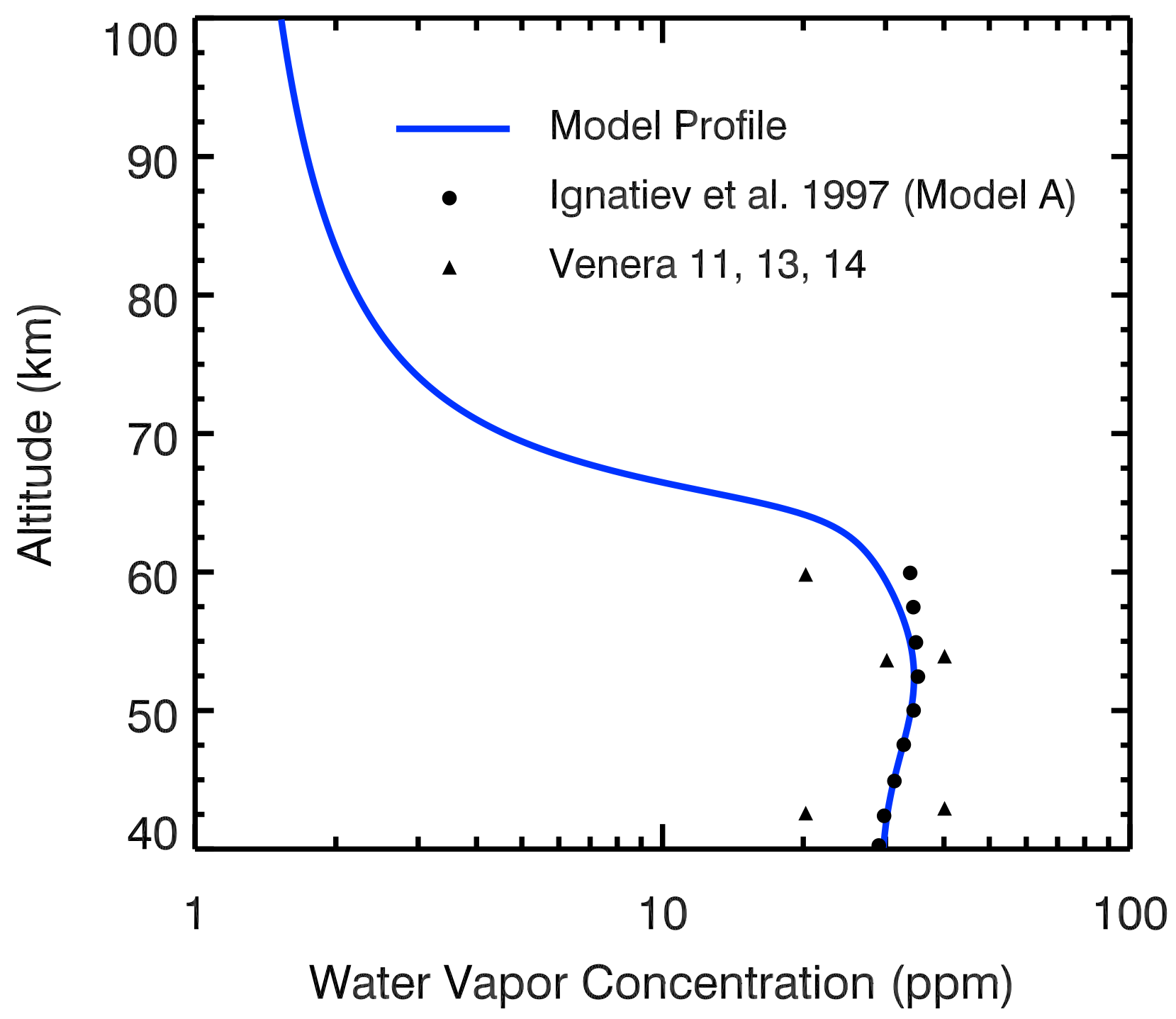

1084

1085

1086

1087

1088

1089

1090

1091

1092
Figure 3. Model water vapor profile (blue) plotted with the Model A (filled circles) and Venera 11,13 , and 14 data (triangles) from Ignatiev et al. (1997). The water vapor concentration in the upper haze is taken to be $\sim 1 \mathrm{ppm}$ from observations by Bertaux et al. (2007). 


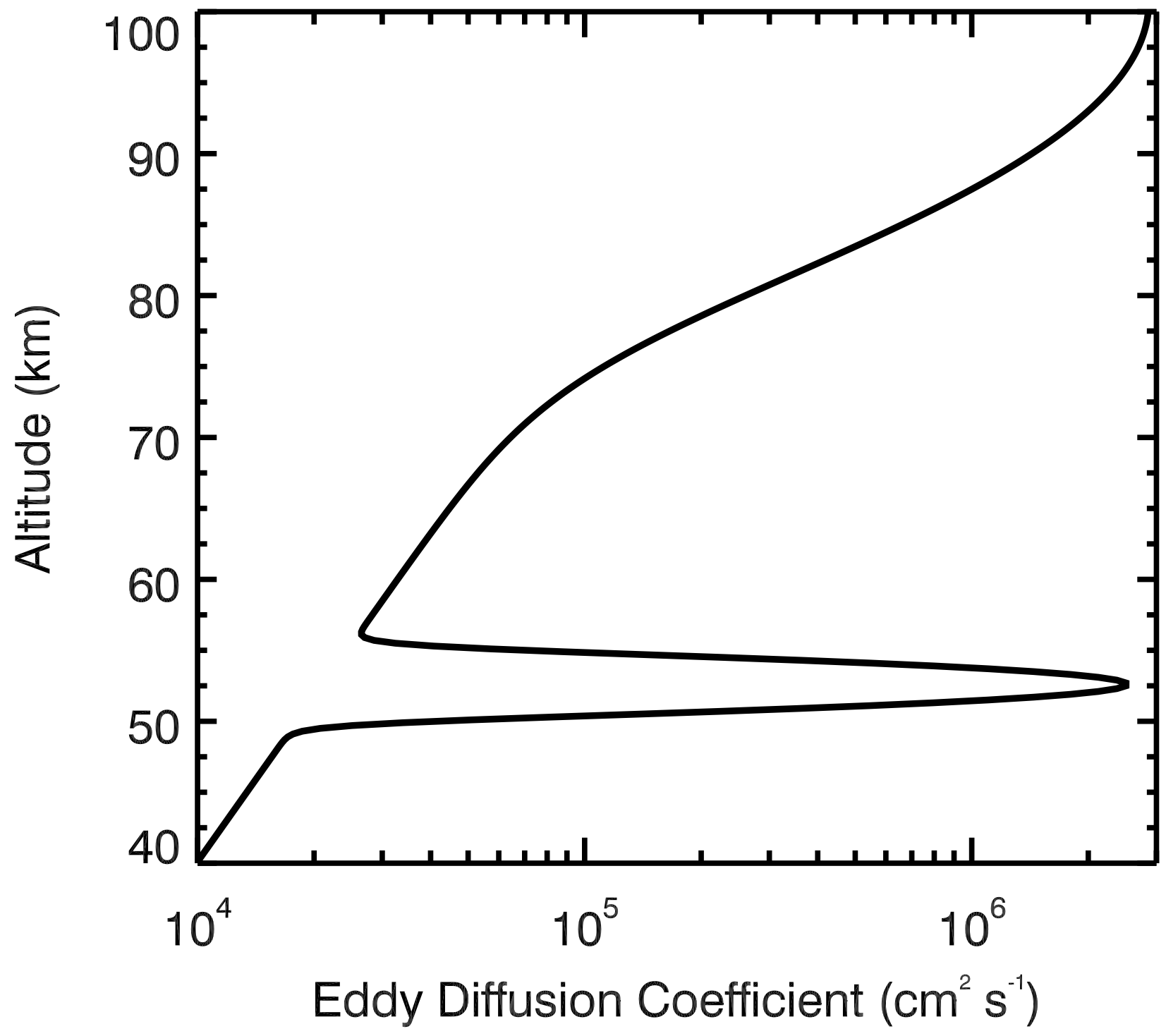

Figure 4. Model eddy diffusion coefficient profile, with the 40-70 $\mathrm{km}$ section based on Imamura and Hashimoto (2001), and the 70-100 km section based on Krasnopolsky (1983). 


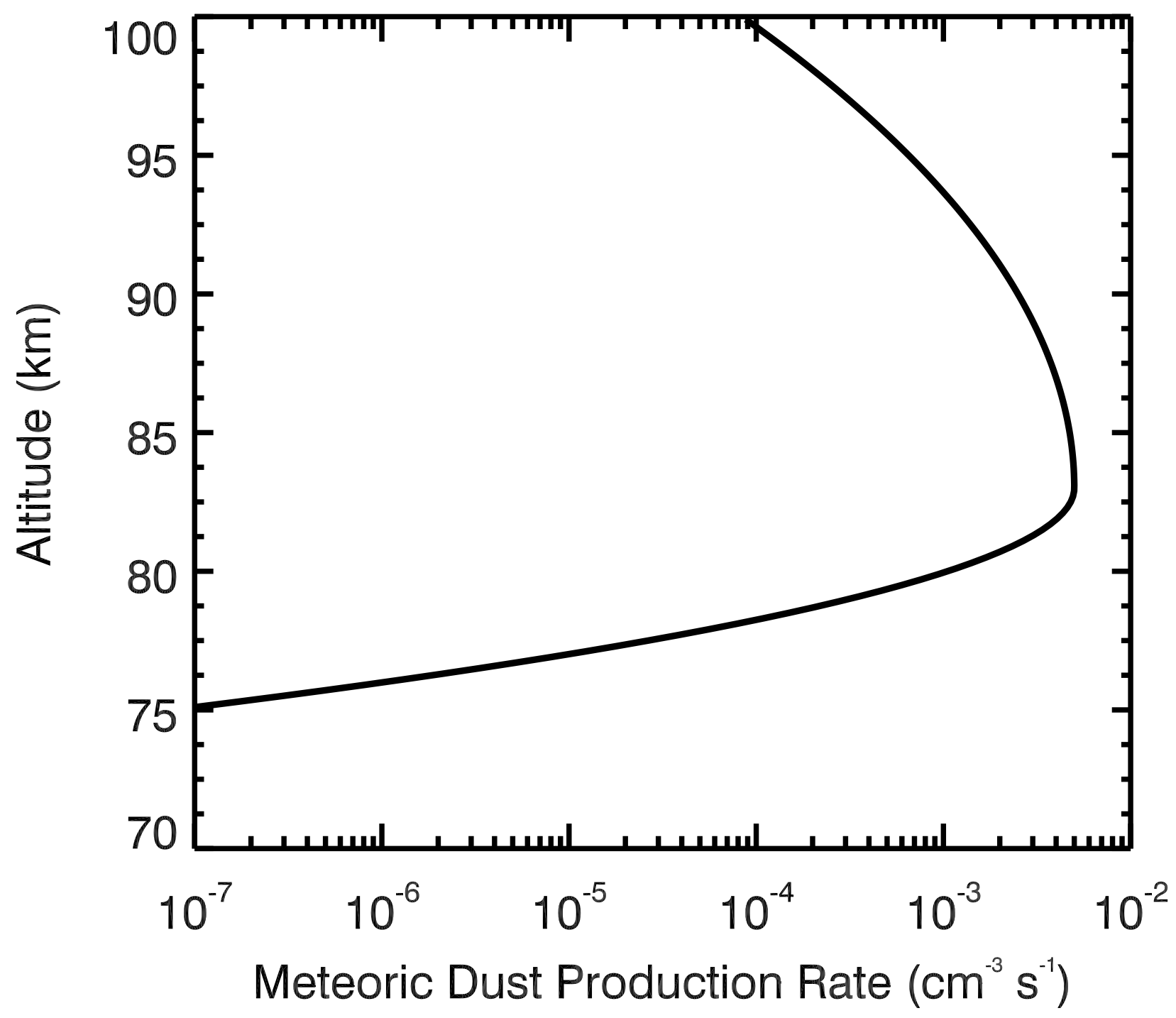

Figure 5. Model meteoric dust production rate profile, based on Kalashnikova et al. (2000), normalized to $1.3 \mathrm{~nm}$ particles, and shifted down from the original distribution by $4 \mathrm{~km}$ in order for the maximum of this profile to match that of the number density profile of the small mode 


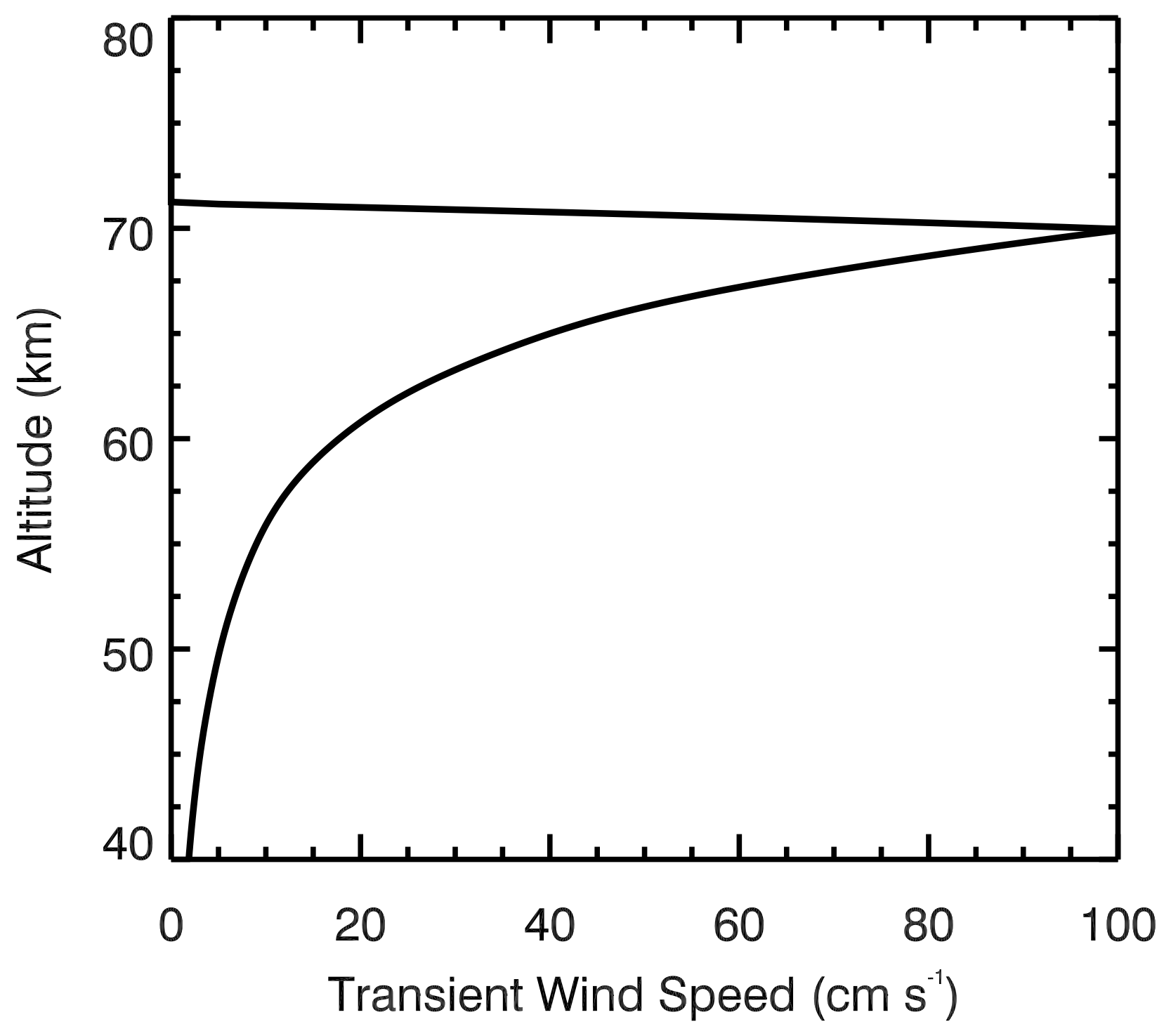

Figure 6. Model wind speed profile with the portion below $70 \mathrm{~km}$ taken from Imamura and 


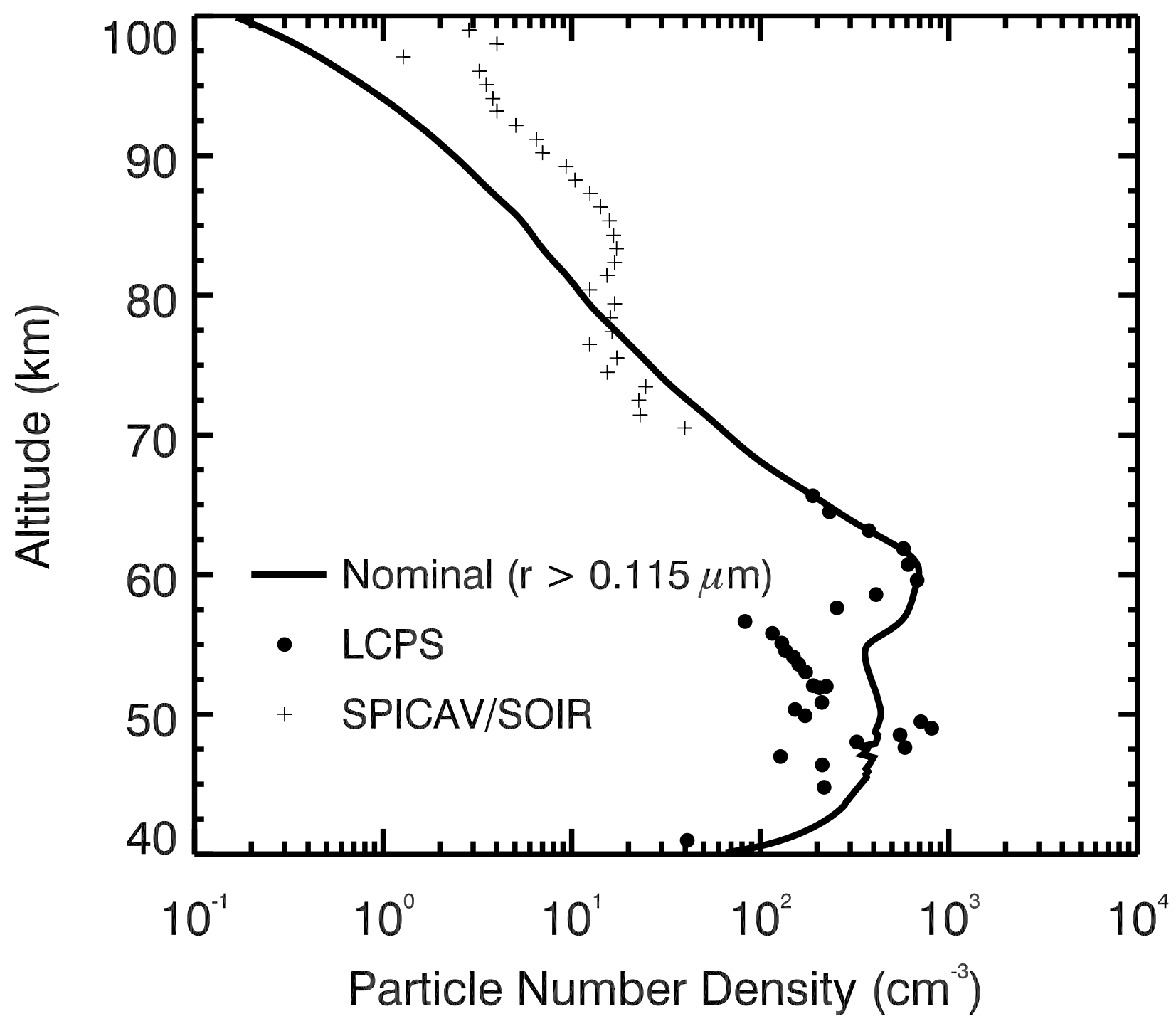

1114

1115

1116

1117

1118

1119

1120
Figure 7. Number density of cloud and haze particles with radius $r>0.115 \mu \mathrm{m}$ (solid line) from the nominal model compared to total number density data from LCPS (filled circles) (Knollenberg and Hunten 1980) and Venus Express (pluses) (Wilquet et al. 2009). 

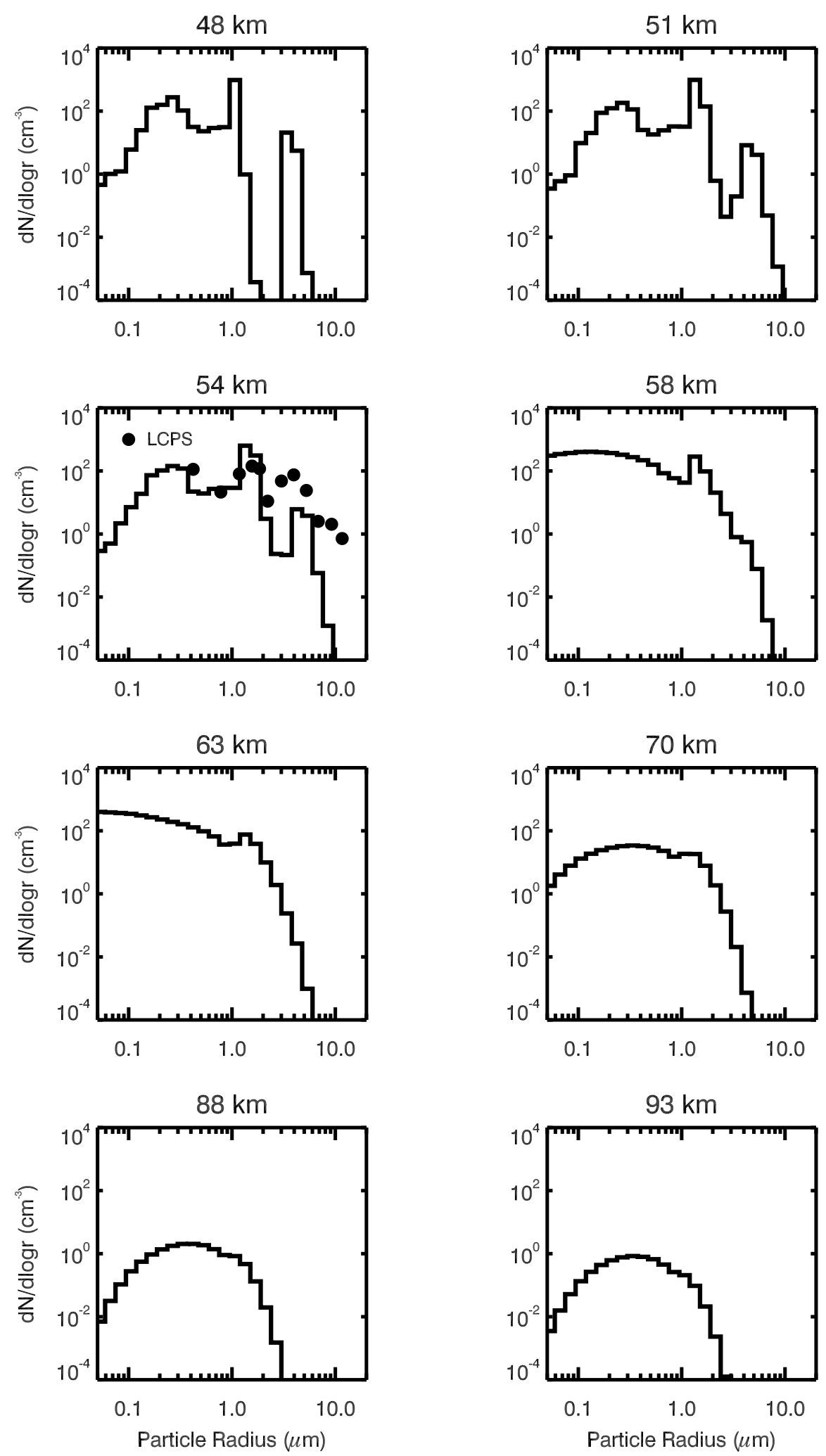

Figure 8. Particle size distributions at various altitudes from the nominal model. LCPS size data 1124 at $54.2 \mathrm{~km}$ (dots) (Knollenberg and Hunten 1980) is plotted for comparison. 


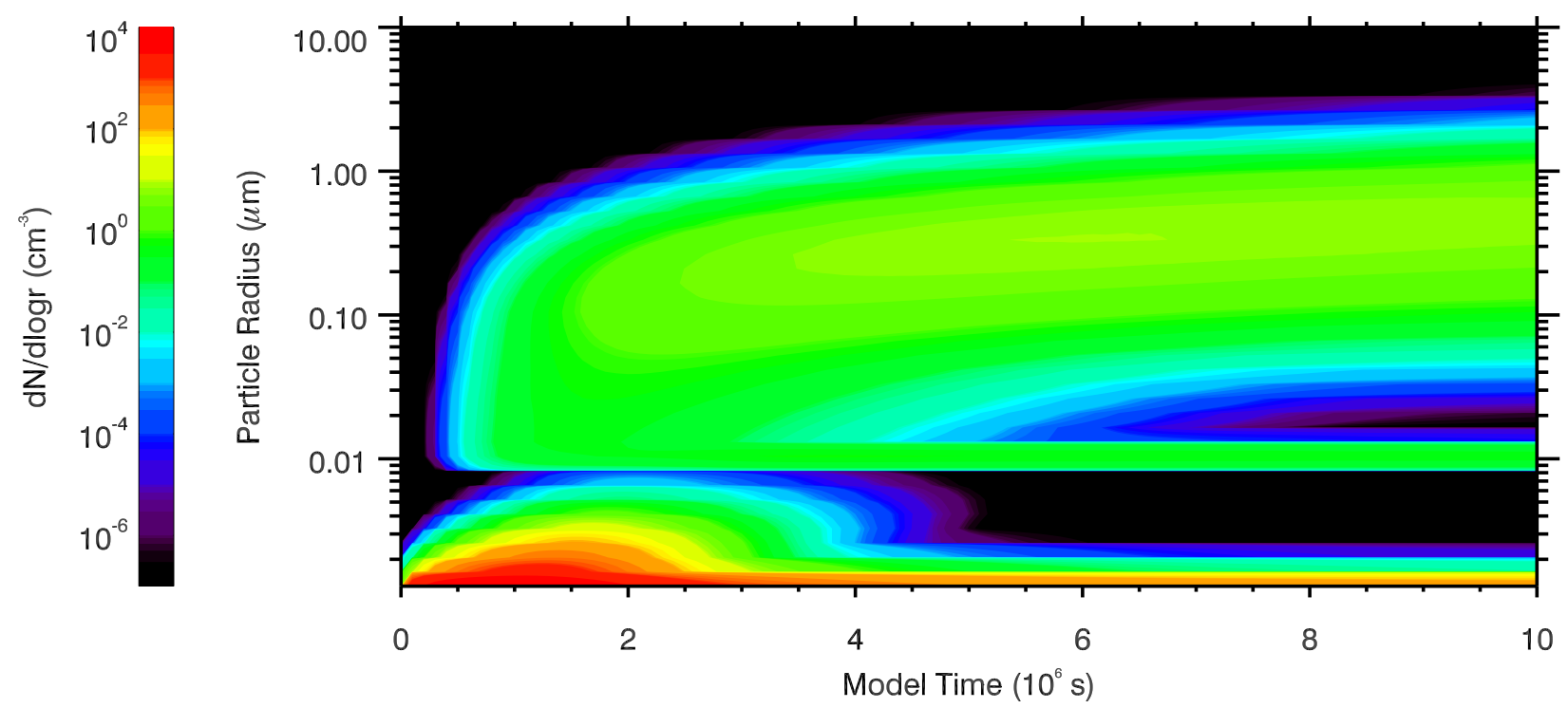

1128 Figure 9. Time evolution of the UH particle size distribution at $84 \mathrm{~km}$ at the beginning of the 1129 nominal model run, from $\mathrm{t}=0$ to $\mathrm{t}=10^{7} \mathrm{~s}$. The green "bar" at $10 \mathrm{~nm}$ is a result of the artificial 1130 injection of $10 \mathrm{~nm}$ particles into the model domain as photochemical condensation nuclei and 1131 should be ignored. The black regions represent parts of the phase space where $\mathrm{dN} / \mathrm{d} \operatorname{logr}<10^{-7}$ $1132 \mathrm{~cm}^{-3}$.

1133

1134 


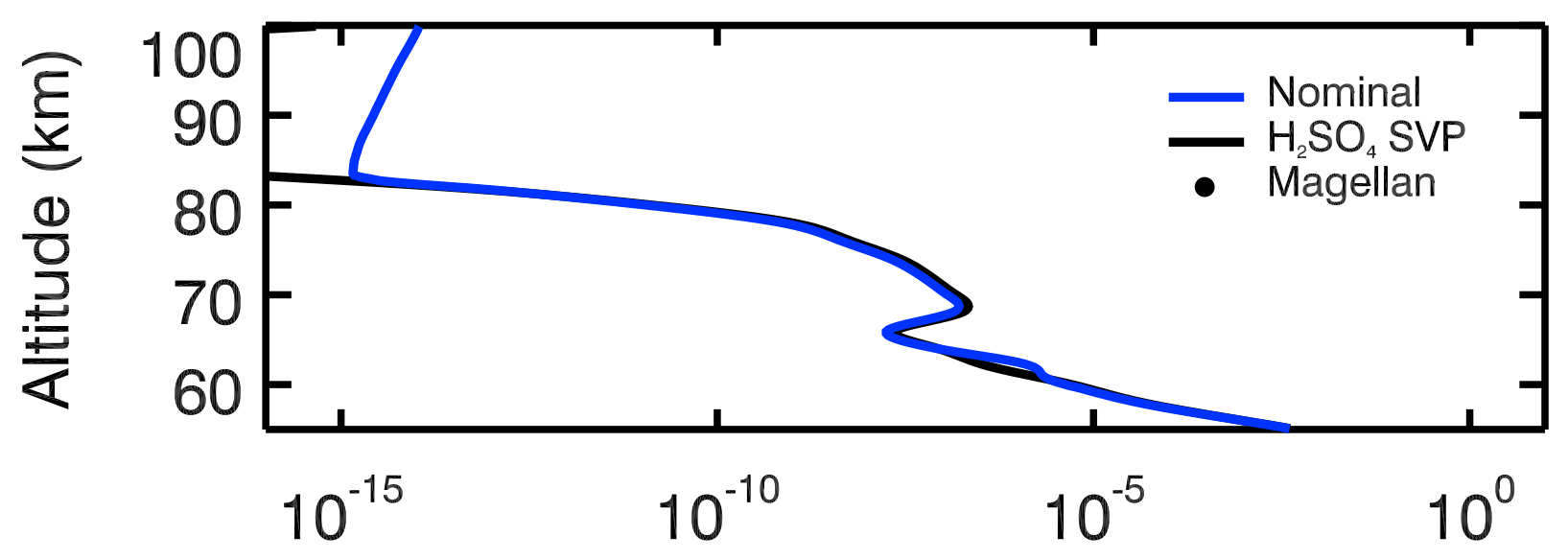

1135

1136

1137

1138

1139

1140

1141

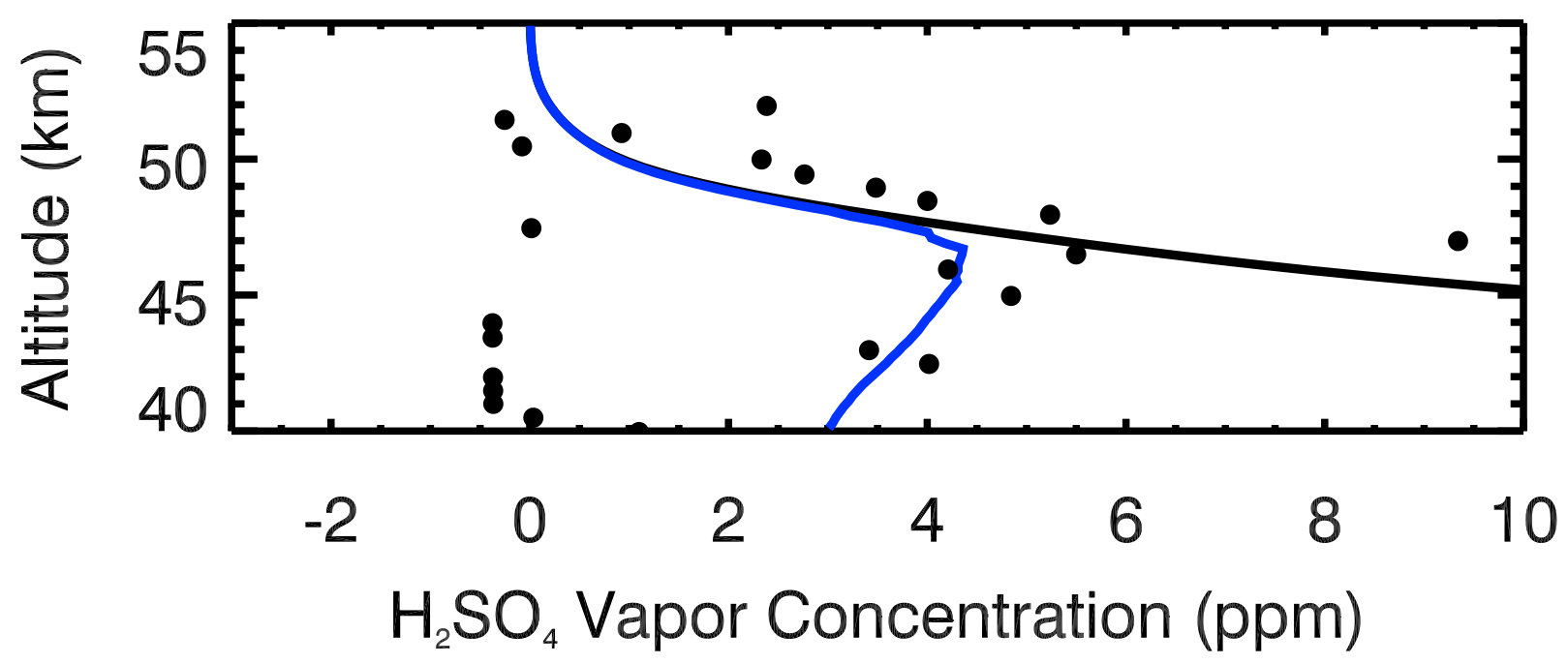

Figure 10. Sulfuric acid vapor mixing ratio from the nominal model (blue) compared with the sulfuric acid saturation vapor pressure over a flat surface (black) (sec. 2.2) and Magellan radio occultation data analyzed by Kolodner and Steffes (filled circles) (1998). 


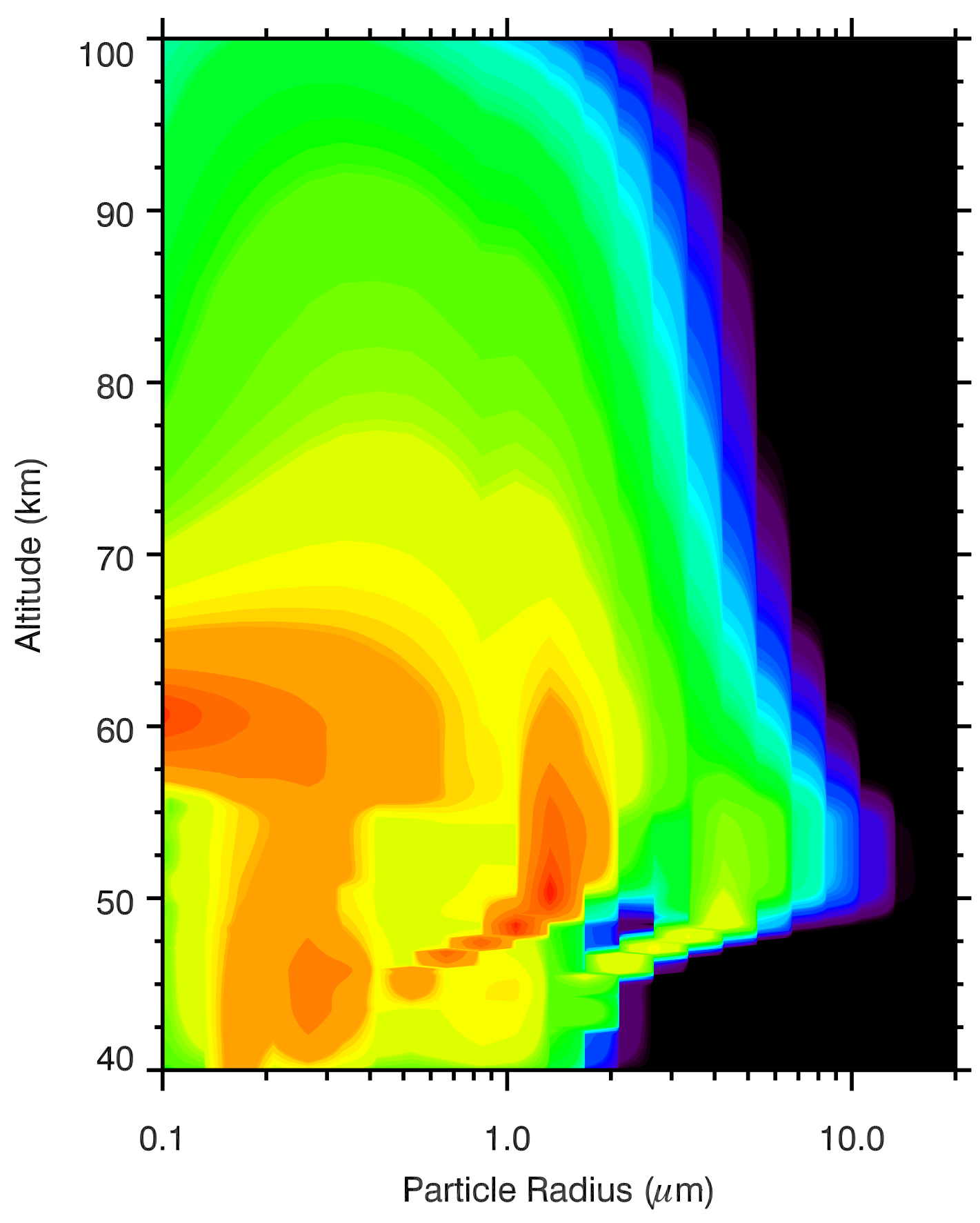

1144 Figure 11. The nominal particle number density as a function of particle size and altitude. The 1145 black regions represent parts of the phase space where $\mathrm{dN} / \mathrm{d} \operatorname{logr}<10^{-7} \mathrm{~cm}^{-3}$. 

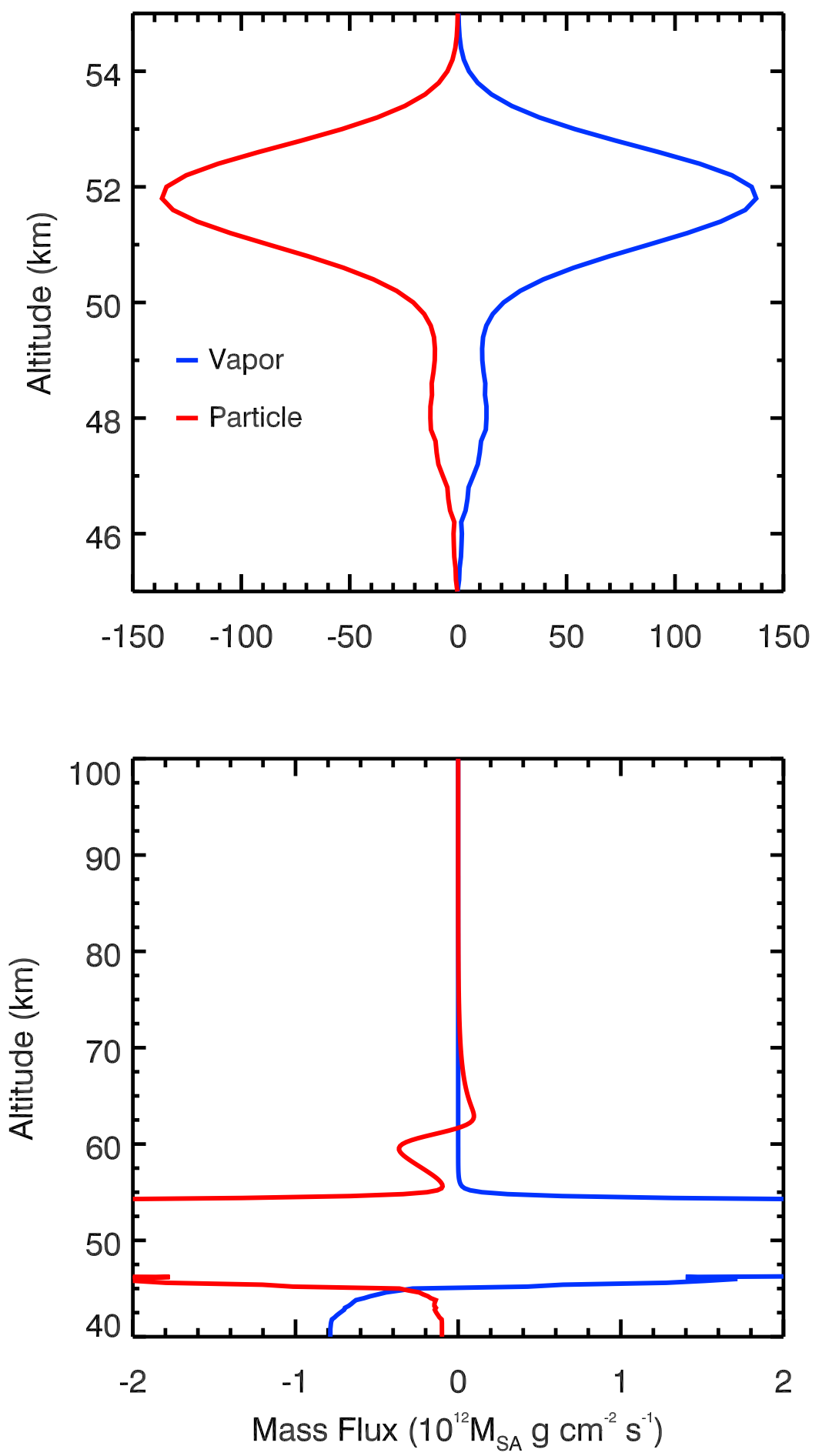

Figure 12. The nominal sulfuric acid vapor (blue) and particle (red) mass fluxes at steady state at 1149 the same time step as in figures 7, 8, 10, and 11 expressed in units of mass equivalent to $10^{12}$ sulfuric acid molecules per unit area per second, where each molecule has mass $\mathrm{M}_{\mathrm{SA}} \sim 1.6 \times 10^{-}$ ${ }^{22} \mathrm{~g}$. Note the different axes scales between the top and bottom panels: the top panel shows the high flux values of the middle cloud, while the bottom panel shows the lower flux values at the other altitudes. 

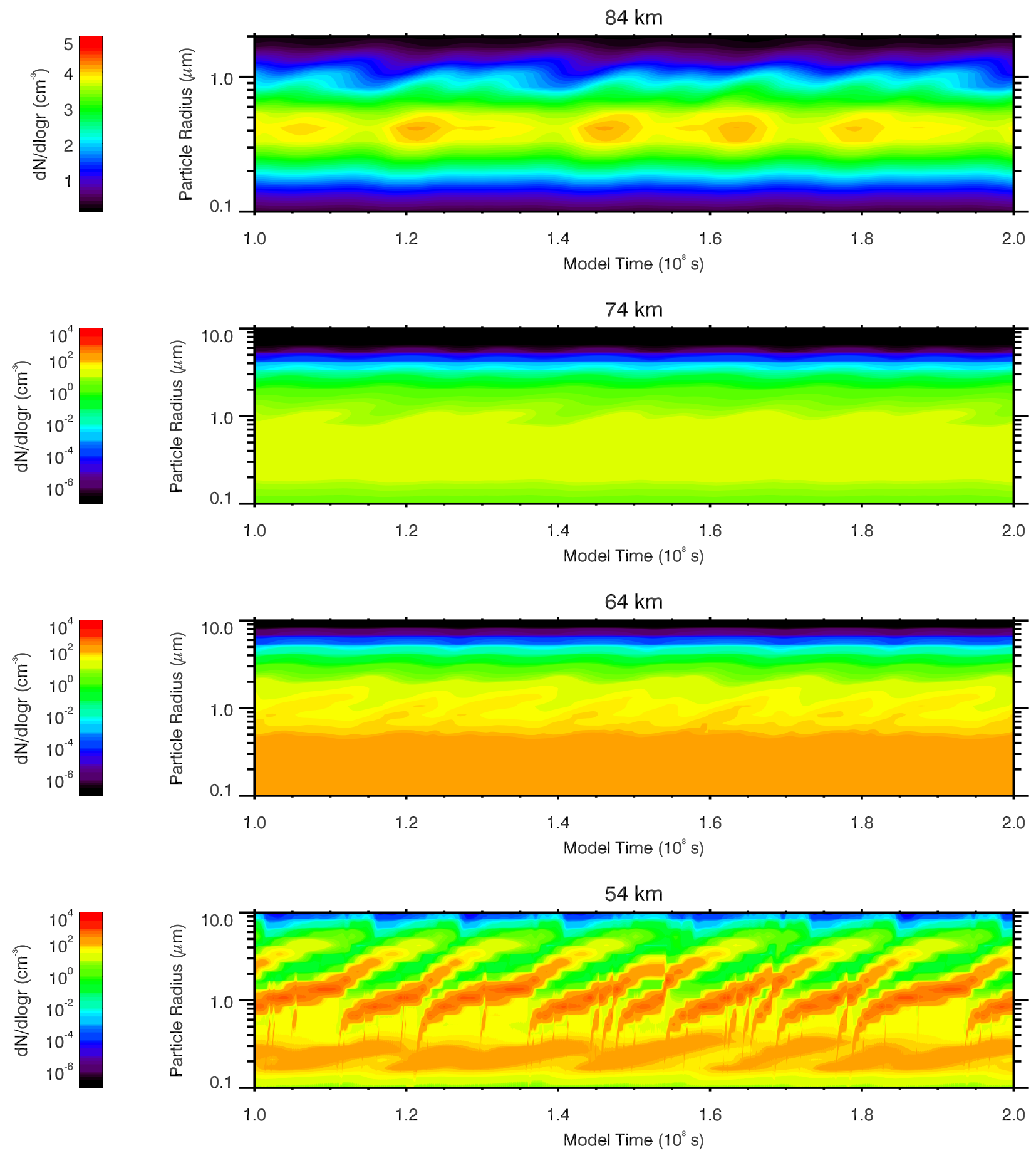

Figure 13. Time evolution of the nominal particle size distribution at $84,74,64$, and $54 \mathrm{~km}$ from $1157 \mathrm{t}=10^{8} \mathrm{~s}$ to $\mathrm{t}=2 \times 10^{8} \mathrm{~s}$. Note the different number density contour and y axis scale for the $84 \mathrm{~km}$ 1158 plot. The black regions represent parts of the phase space where $\mathrm{dN} / \mathrm{d} \operatorname{logr}<10^{-7} \mathrm{~cm}^{-3}$ at 74,64 , 1159 and $54 \mathrm{~km}$, and $<0.1 \mathrm{~cm}^{-3}$ at $84 \mathrm{~km}$. 


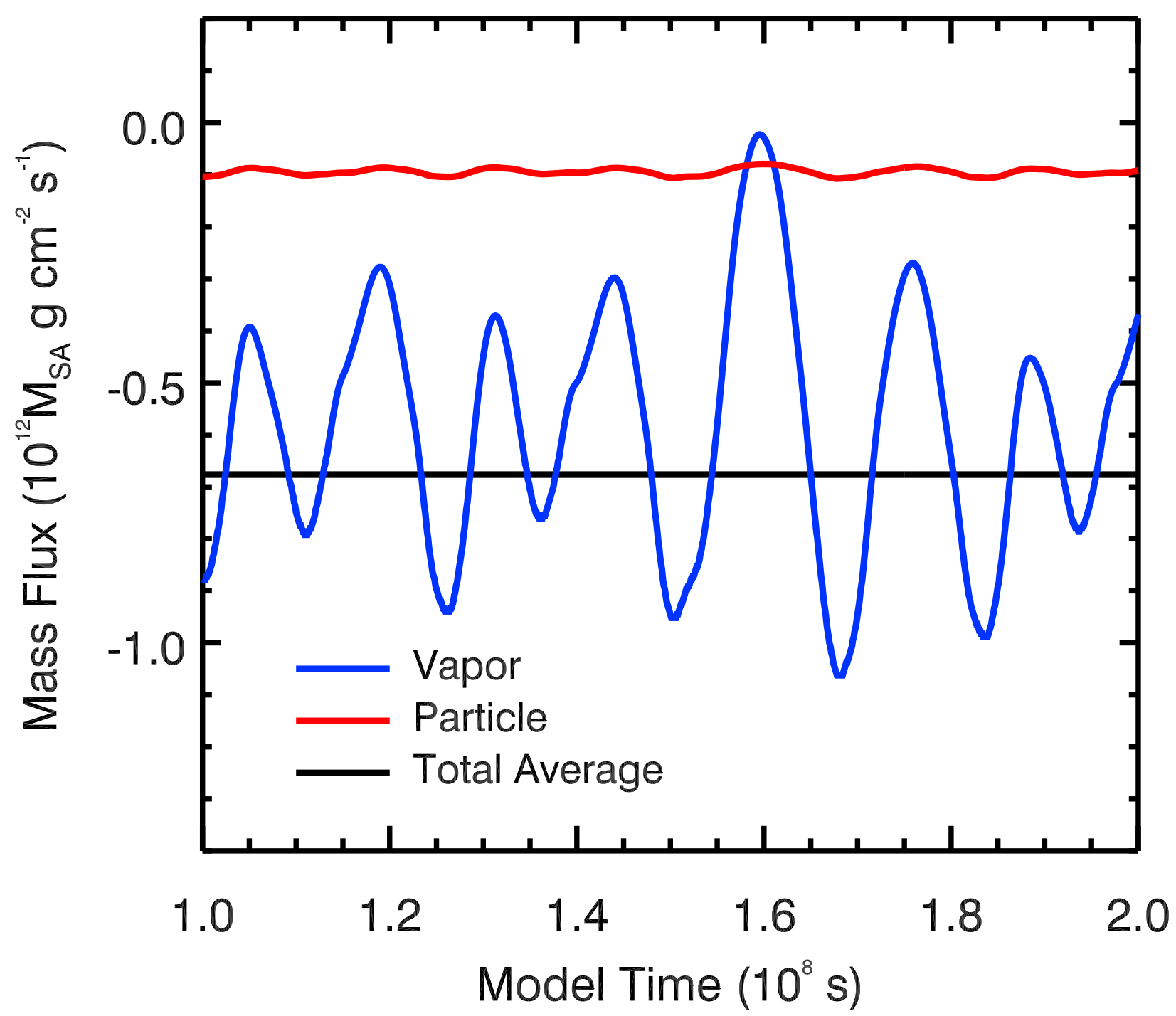

1164 Figure 14. The time evolution of the nominal sulfuric acid vapor (blue) and particle (red) mass 1165 fluxes at the bottom of the model domain from $t=10^{8} \mathrm{~s}$ to $\mathrm{t}=2 \times 10^{8} \mathrm{~s}$ plotted with the average 1166 of the total flux during this time period (black), all expressed in units of mass equivalent to $10^{12}$ 

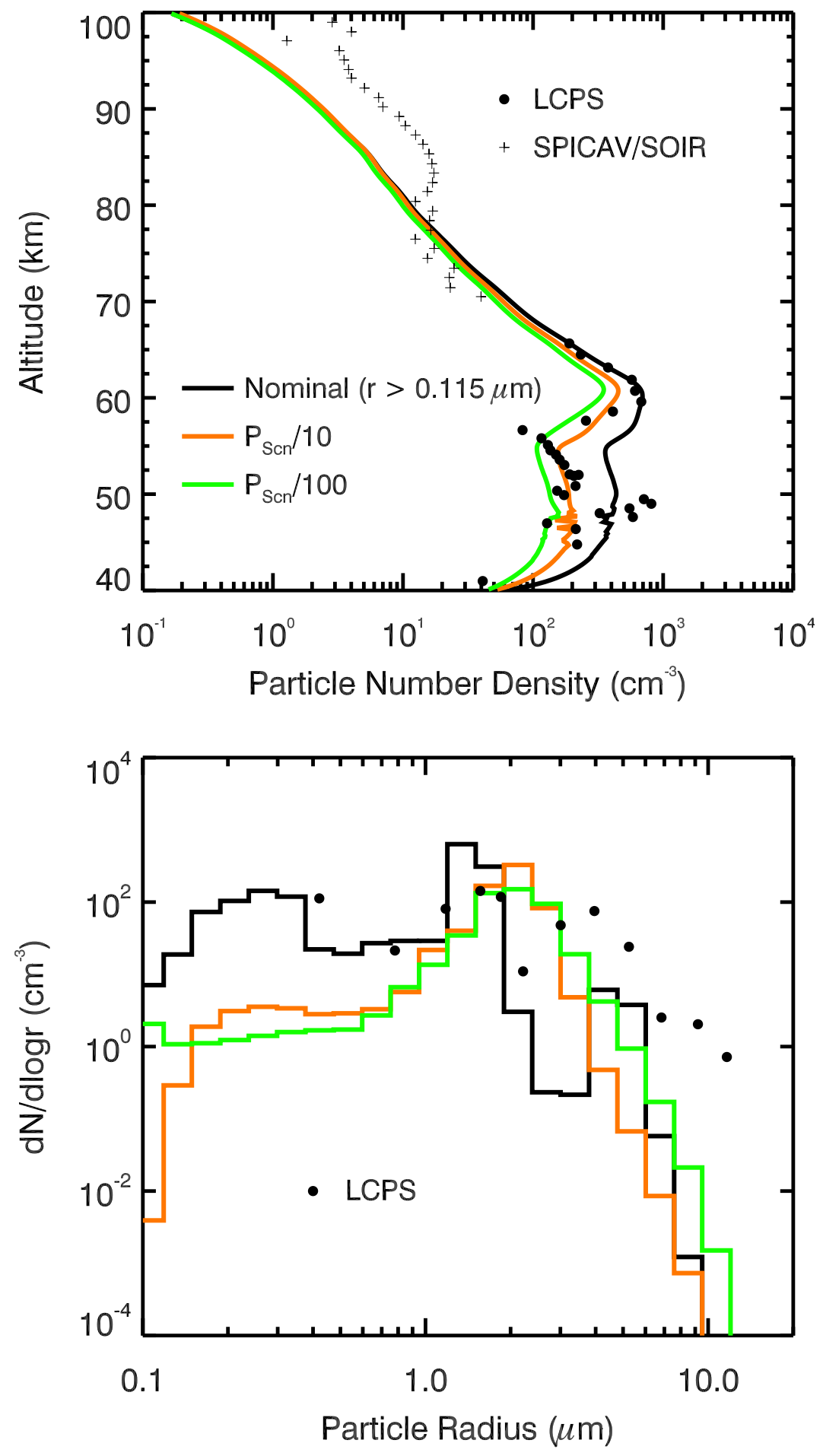

1172

1173

1174

1175

1176

1177

1178
Figure 15. The number density (top) and size distribution at $54 \mathrm{~km}$ (bottom) of the nominal (black), one order of magnitude reduction in sulfur production (orange), and two orders of magnitude reduction in sulfur production (green) cases. The curves in the top figure are compared to total number density data from LCPS (filled circles) (Knollenberg and Hunten 1980) and Venus Express (pluses) (Wilquet et al. 2009). The histograms in the bottom figure are compared to LCPS size data at $54.2 \mathrm{~km}$ (filled circles) (Knollenberg and Hunten 1980). 


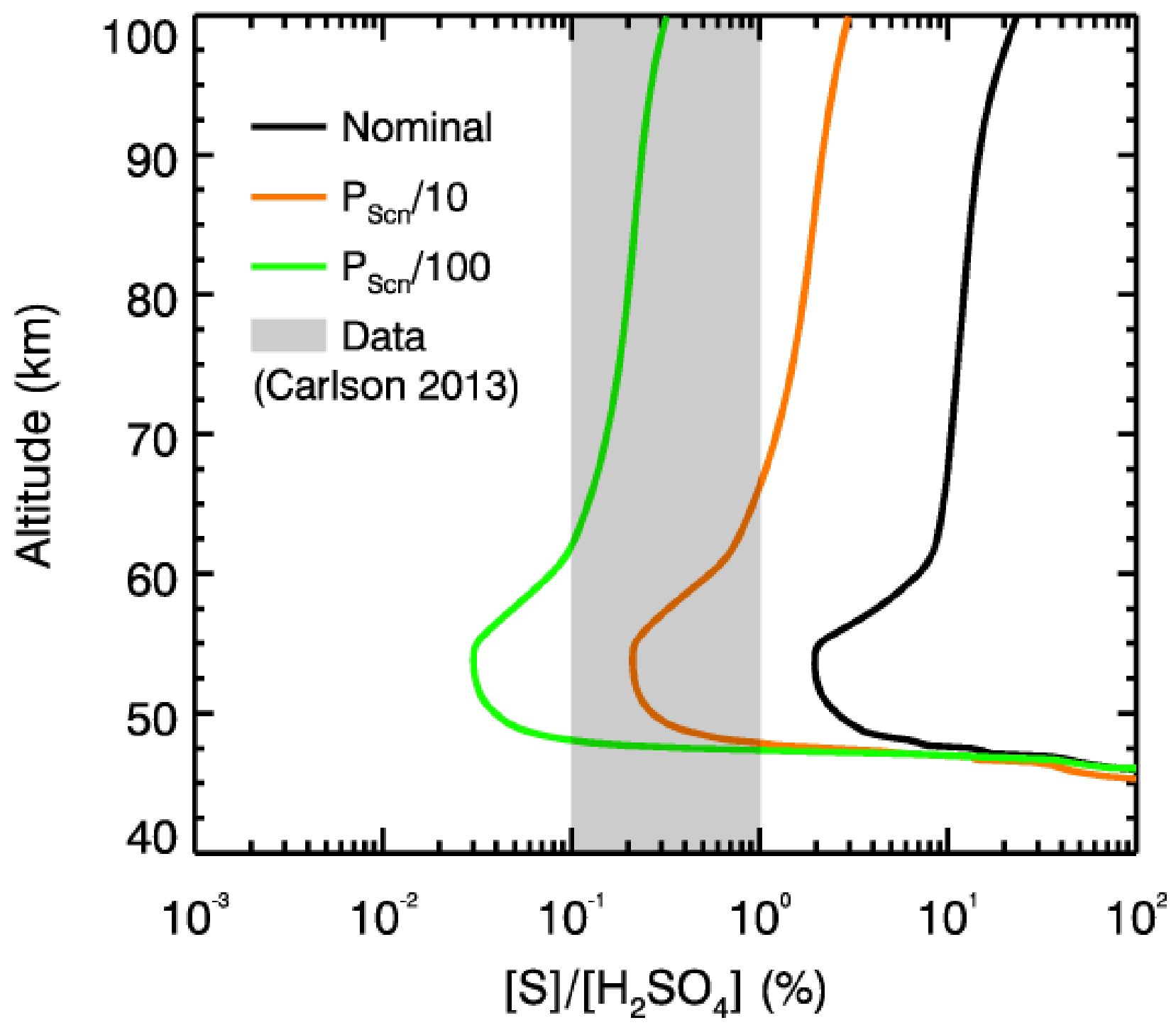

Figure 16. The average mass ratio of sulfur to sulfuric acid in cloud and haze droplets as a 1181 function of altitude for the nominal (black), one order of magnitude reduction in sulfur production (orange), and two orders of magnitude reduction in sulfur production (green) cases. 1186 


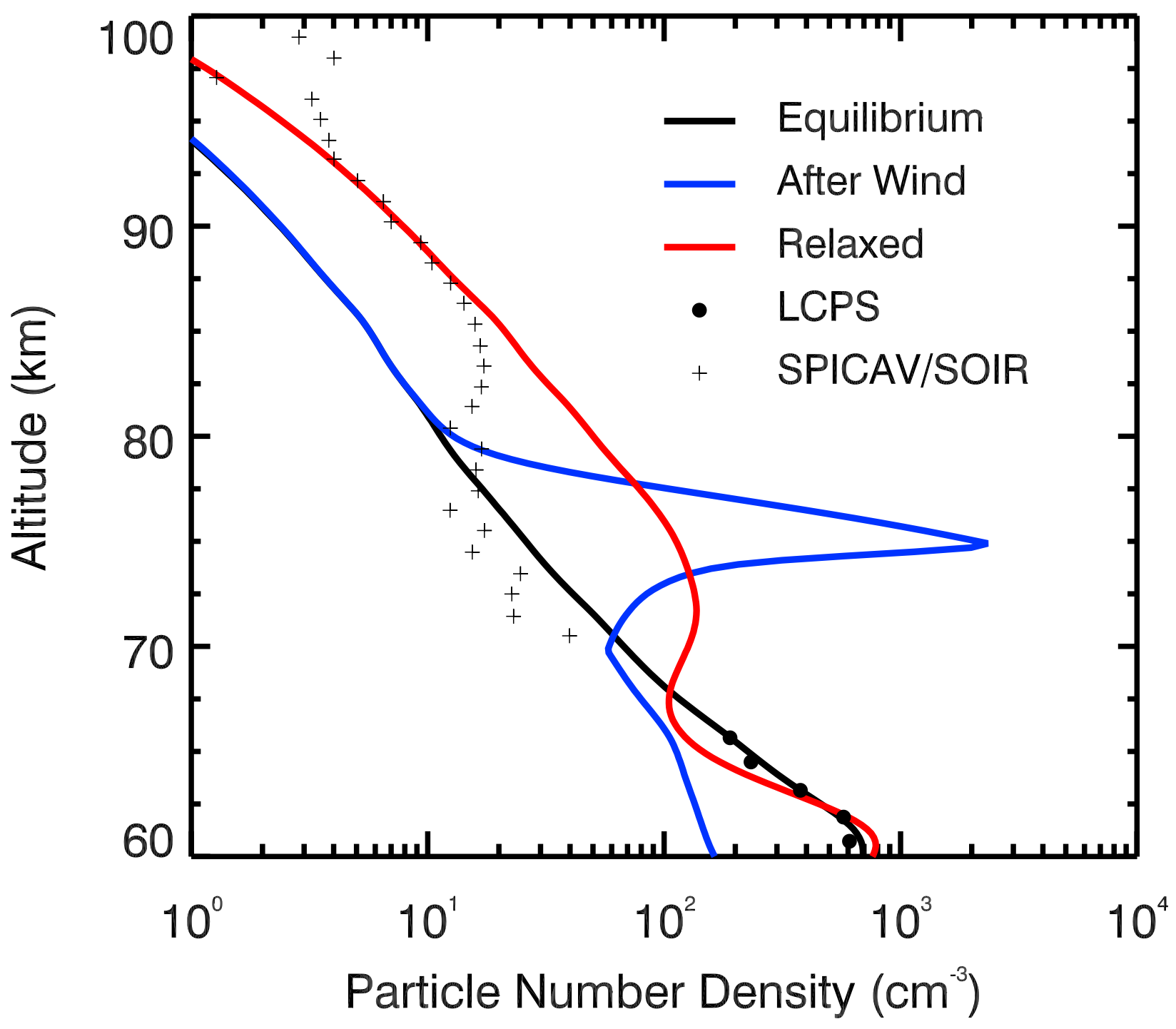

Figure 17. Number density profiles of the upper cloud and haze before (black), immediately after (blue), and $5 \times 10^{5} \mathrm{~s}$ after (red) a $5 \times 10^{4} \mathrm{~s}$ transient wind event. The total number density data from LCPS (filled circles) (Knollenberg and Hunten et al. 1980) and Venus Express (pluses) 

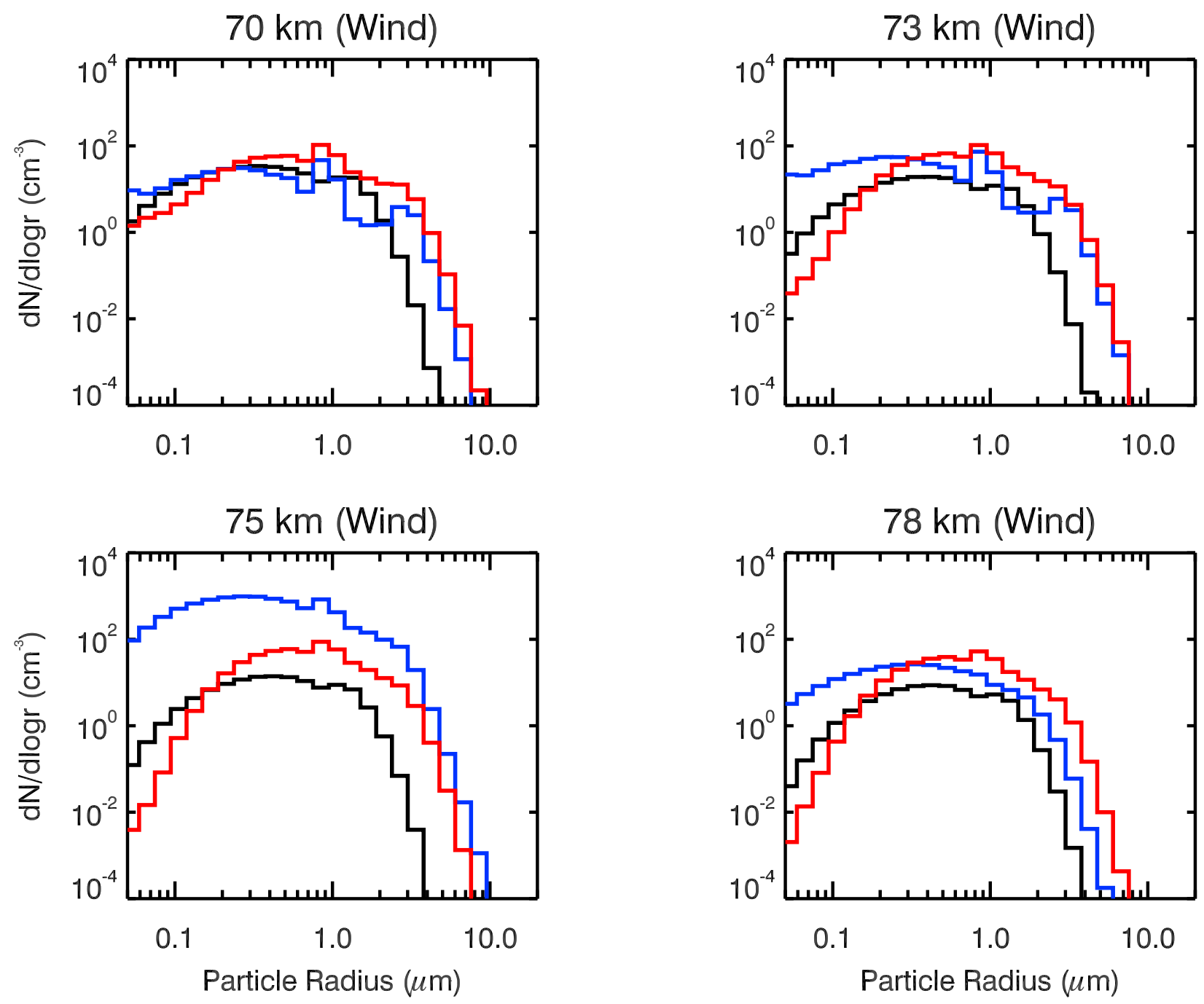

Figure 18. Particle size distribution before (black), immediately after (blue), and $5 \times 10^{5} \mathrm{~s}$ after 1200 (red) a $5 \times 10^{4} \mathrm{~s}$ transient wind event, plotted for various altitudes close to the turnover altitude of the transient wind. The wind speed profile is shown in Fig. 6. 


\begin{tabular}{|c|c|c|}
\hline & Nominal Model & Other Values Used \\
\hline Surface Gravity & $887.0 \mathrm{~cm} \mathrm{~s}^{-2}$ & \\
\hline Atmospheric Mole. Wt. & $43.45 \mathrm{~g} \mathrm{~mol}^{-1}\left(\mathrm{CO}_{2}\right)$ & \\
\hline Condensable Mole. Wt. & $98.08 \mathrm{~g} \mathrm{~mol}^{-1}\left(\mathrm{H}_{2} \mathrm{SO}_{4}\right)$ & \\
\hline Atmospheric Viscosity ${ }^{a}$ & $1.496 \times 10^{-4} \mathrm{~g} \mathrm{~cm}^{-1} \mathrm{~s}^{-1}$ & \\
\hline Sulfuric Acid Surface Tension ${ }^{b}$ & $72.4 \mathrm{erg} \mathrm{cm}^{-2}$ & \\
\hline T-P Profile & Figure 1 & \\
\hline Water Vapor Profile & Figure 3 & \\
\hline \multicolumn{3}{|l|}{ Production Rates } \\
\hline Meteoric Dust & $4800 \mathrm{~cm}^{-2} \mathrm{~s}^{-1}$ (Fig. 5) & \\
\hline Photochemical CNs & $1.75 \times 10^{6} \mathrm{~cm}^{-2} \mathrm{~s}^{-1}$ (Fig. 2) & Nominal $/ 10^{c}$, Nominal $/ 100^{c}$ \\
\hline Sulfuric Acid Vapor & $6 \times 10^{11} \mathrm{~cm}^{-2} \mathrm{~s}^{-1}$ (Fig. 2) & \\
\hline \multicolumn{3}{|l|}{ Time Domain } \\
\hline Time Step & $10 \mathrm{~s}$ & \\
\hline Total Simulation Time & $2 \times 10^{8} \mathrm{~s}$ & $5 \times 10^{4} \mathrm{~s}^{\mathrm{d}}, 5 \times 10^{5} \mathrm{~s}^{\mathrm{d}}$ \\
\hline \multicolumn{3}{|l|}{ Altitude Domain } \\
\hline Thickness of Altitude Level & $200 \mathrm{~m}$ & \\
\hline Total Altitude Levels & 300 & \\
\hline \multicolumn{3}{|l|}{ Size Domain } \\
\hline Mass Ratio Between Bins & 2 & \\
\hline Number of Bins & 45 & \\
\hline Smallest Bin Size & $1.3 \mathrm{~nm}$ & \\
\hline Photochemical CN Size & $10.4 \mathrm{~nm}^{\mathrm{e}}$ & \\
\hline \multicolumn{3}{|l|}{ Initial Conditions } \\
\hline Meteoric Dust & $0 \mathrm{~cm}^{-3}$ & \\
\hline Photochemical CNs & $0 \mathrm{~cm}^{-3}$ & \\
\hline Sulfuric Acid Vapor & $0 \mathrm{ppm}$ & \\
\hline \multicolumn{3}{|l|}{ Boundary Conditions } \\
\hline Meteoric Dust (Top) & Zero flux & \\
\hline Photochemical CNs (Top) & Zero flux & \\
\hline Sulfuric Acid Vapor (Top) & Zero flux & \\
\hline Meteoric Dust (Bottom) & $0 \mathrm{~cm}^{-3}$ & \\
\hline Photochemical CNs (Bottom) $\mathrm{f}$ & $40 \mathrm{~cm}^{-3}$ & \\
\hline Sulfuric Acid Vapor (Bottom) & $3 \mathrm{ppm}$ & \\
\hline Wind Speed & $0 \mathrm{~cm} \mathrm{~s}^{-1}$ & Figure $6^{\mathrm{d}}$ \\
\hline
\end{tabular}

\footnotetext{
${ }^{a}$ Value at $300 \mathrm{~K}$. Viscosity dependence on temperature is calculated using Sutherland's equation and parameters from White (1991).

${ }^{\mathrm{b}}$ Value for a flat surface at $\sim 60 \mathrm{~km}$, where temperature $\sim 260 \mathrm{~K}$ and sulfuric acid weight percentage of sulfuric acid droplets $\sim 80 \%$.

${ }^{\mathrm{c}}$ See Sec. 3.3.

${ }^{\mathrm{d}}$ For transient wind tests (Sec. 2.6 and 3.4).

${ }^{\mathrm{e}}$ We use $10.4 \mathrm{~nm}$ instead of $10 \mathrm{~nm}$ as $10.4 \mathrm{~nm}$ corresponds to the radius represented by one of the discrete size bins in our model (bin 10).
} 
$1213{ }^{\mathrm{f}}$ These photochemical CNs have radius $\sim 0.17 \mu \mathrm{m}$, consistent with the mean size of the particles 1214 at $\sim 40 \mathrm{~km}$ observed by Pioneer Venus LCPS (Knollenberg and Hunten 1980).

1215 